\title{
Parameterizing ice nucleation rates using contact angle and activation energy derived from laboratory data
}

\author{
J.-P. Chen ${ }^{1}$, A. Hazra ${ }^{1}$, and Z. Levin ${ }^{2}$ \\ ${ }^{1}$ Department of Atmospheric Sciences, National Taiwan University, Taiwan \\ ${ }^{2}$ Department of Geophysics and Planetary Sciences, Tel Aviv University, Israel
}

Received: 29 May 2008 - Published in Atmos. Chem. Phys. Discuss.: 29 July 2008

Revised: 17 November 2008 - Accepted: 17 November 2008 - Published: 15 December 2008

\begin{abstract}
The rate of ice nucleation in clouds is not easily determined and large discrepancies exist between model predictions and actual ice crystal concentration measured in clouds. In an effort to improve the parameterization of ice nucleating in cloud models, we investigate the rate of heterogeneous ice nucleation under specific ambient conditions by knowing the sizes as well as two thermodynamic parameters of the ice nuclei - contact angle and activation energy. Laboratory data of freezing and deposition nucleation modes were analyzed to derive inversely the two thermodynamic parameters for a variety of ice nuclei, including mineral dusts, bacteria, pollens, and soot particles. The analysis considered the Zeldovich factor for the adjustment of ice germ formation, as well as the solute and curvature effects on surface tension; the latter effects have strong influence on the contact angle. Contact angle turns out to be a more important factor than the activation energy in discriminating the nucleation capabilities of various ice nuclei species. By extracting these thermodynamic parameters, laboratory results can be converted into a formulation that follows classical nucleation theory, which then has the flexibility of incorporating factors such as the solute effect and curvature effect that were not considered in the experiments. Due to various uncertainties, contact angle and activation energy derived in this study should be regarded as "apparent" thermodynamics parameters.
\end{abstract}

\section{Introduction}

Ice processes in clouds are important to precipitation formation, thus the hydrological cycle. As Lau and Wu (2003) pointed out, more than $50 \%$ of the mid-latitude precipita-

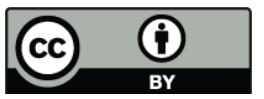

Correspondence to: J.-P. Chen

(jpchen@as.ntu.edu.tw) tion is produced via cold-cloud (involving ice) processes, whereas in the tropical region the proportion reaches $30 \%$. The initiation of ice formation and cloud glaciation at temperatures above about $-35^{\circ} \mathrm{C}$ usually requires the presence of ice nucleating particles. These so-called ice nuclei (IN) can lower the energy barriers of ice nucleation so that ice particles can be produced heterogeneously in relatively warm environments. They can initiate ice through the deposition mode, condensation-freezing mode, contact freezing mode or the immersion mode (Pruppacher and Klett, 1997, p. 309).

Detailed information on atmospheric IN is rather scarce. Earlier studies measured the bulk concentration of atmospheric IN without knowing the physical or chemical properties of individual particles. Some of them characterized the ice nucleating capability of IN with the so-called "threshold temperature" (e.g., Heffernan and Bracewell, 1959; Isono et al., 1959; Carte and Mossop, 1960; Fletcher, 1962; Cooper and Saunders, 1980; Bowdle et al., 1985). However, many observational studies have shown that the number concentration of ice crystals in clouds is not strictly determined by temperature (e.g., Gultepe et al., 2001; Korolev et al., 2003). In fact, the ice nucleating capability in the deposition mode can be better characterized with the degree of supersaturation with respect to ice (e.g., Bryant et al., 1959; Huffman, 1973; Hussain and Saunders, 1984; Stein and Georgii, 1982; DeMott et al., 1998; Möhler et al., 2006). But such notion is not in accordance with the classical theory for heterogeneous ice nucleation. According to classical theory, nucleation should be a probabilistic rate process, meaning that only a certain proportion of a particular kind of nuclei can be activated into ice in a specific length of time. A contrasting view of nucleation is called the "singular model" which considers nucleation to be controlled by impurity or by active site on the surface of ice nuclei, where each site has a characteristic temperature (for freezing nucleation) or saturation ratio (for deposition nucleation) (Dorsey, 1948). Under such a concept, time is not an important factor and no new nucleation can occur if

Published by Copernicus Publications on behalf of the European Geosciences Union. 
environmental conditions remain the same. This also implies that IN which nucleate at different temperatures (or supersaturation) should possess different surface characteristics or sizes, while identical IN must nucleate all together at the same environment conditions. Note that our study is based on the classical (statistical) nucleation theory, but we noted the uncertainty associated with it and will provide further discussion on this issue in Sect. 4.4. The above threshold concept is adopted popularly in many meteorological cloud models. Their formulations present the number of ice particles, generated through deposition or condensation-freezing nucleation, as a function of either temperature or ice supersaturation, or a combination of the two variables (e.g., Fletcher, 1962; Wisner et al., 1972; Cotton et al., 1982; Lin et al., 1983; Myers et al., 1992; Reisner et al., 1998). Although easy to use, such formulations have several deficiencies. First, the formulas are mostly empirical and do not consider the temporal and spatial variations of atmospheric IN. Take the empirical formula of Fletcher (1962) as an example; the amount of active IN is expressed as a function of temperature only. Yet, the concentration of atmospheric IN does vary tremendously in time and space, as well as in their origins. Furthermore, by treating the nucleation process in a diagnostic way, such schemes cannot handle the situations when IN actually have been consumed earlier even in the same cloud, thus they tend to over-predict the number of ice particles. It is also impossible to recount the IN when the ice particles formed on them evaporate. Furthermore, these empirical formulas obviously lose track of individual IN, thus are not suitable for evaluating IN of different origins or physical properties such as size.

Simulating accurately the ice-phase processes remains a difficult task for cloud modelers to this date. Among the main difficulties are the lack of knowledge about the properties and distribution of IN. A few species of IN have been identified as important ice initiation agent in the atmosphere, such as mineral dust (Kumai, 1951; Isono et al., 1959), volcanic ashes (Isono and Kombayashi, 1954; Isono et al., 1959), combustion particles (Hobbs and Locatelli, 1969; DeMott, 1990), and bio-aerosols which include whole organisms (e.g. bacteria, fungi, and phytoplankton), reproductive materials (e.g. pollens and spores) and plant fragments (Schnell and Vali, 1973; Schnell, 1974; Levin et al., 1987; Diehl et al., 2001). As will be discussed later, significant progress has been made recently in laboratory measurements of ice nucleation rates of various IN. Combined with increasing model capability of simulating the emission and transport of atmospheric IN species (e.g., Lighthart, 1997; Uno et al., 2003; Chen et al., 2004; Kishcha et al., 2005; Pasken and Pietrowicz, 2005), the next generation meteorological models may be able to adequately examine the roles that major IN play in precipitation formation. Such work would be important to the understanding of interactions between land surface (including the ecosystem) and the atmospheric hydrologic cycle (Barth et al., 2005).
Laboratory derived ice nucleation rates can be used adequately in models that resolve cloud microphysics for treatment of single or multiple IN species. However, few attempts have been made to extract from these data useful information related to the properties of IN. Based on classical nucleation theory, Khvorostyanov and Curry (2004) parameterized the heterogeneous freezing of deliquescent interstitial aerosols to serve as ice nuclei and used the results to explain empirical observations. However, their parameterization was purely theoretical and did not utilize the information provided by laboratory measurements of ice nucleation. If fundamental thermodynamic properties of IN can be obtained, they may not only help us understand the physical mechanisms of nucleation but also broaden the application of laboratory results by providing better parameterization for ice nucleation in cloud models. For example, ice nuclei, such as mineral dust, often contain a solute coating that helps to acquire liquid water for freezing. Yet, freezing nucleation experiments often were conducted under pure water conditions, and it is difficult to include solute effect into empirical rate equations derived from these experiments. With the help of fundamental analysis, it may be possible to integrate the solute effect or other factors into the nucleation rate formulas. In this study we intend to show this possibility by re-analyzing laboratory data of ice nucleation from various IN. We then obtain basic thermodynamic parameters as described by the classical theory to provide a more general and accurate parameterization of ice nucleation rate for use in cloud microphysical models.

\section{Method}

In classical nucleation theory, the heterogeneous ice nucleation rates can be calculated by knowing a few key parameters that are specific to each ice nuclei, such as the activation energies and contact angles. If the classical theory holds well, then it is possible to extract these key parameters inversely from laboratory data. Although there have been a number of laboratory studies focused on heterogeneous ice nucleation, few tried to relate the measurement data to these key parameters. Here, we describe the method of analyzing classical formulas of heterogeneous ice nucleation, as well as the laboratory data and apply it to a variety of natural and anthropogenic ice nuclei.

\subsection{Laboratory data}

We focus on four types of IN that are common and potentially important to ice formation in clouds, namely, mineral dust, bacteria, pollen, and soot particles. There might be other effective IN in the atmosphere such as spores, phytoplankton or even virus, but laboratory data on their nucleation characteristics are currently unavailable.

Mineral dust particles have long been identified as a common and efficient IN since Kumai (1951) and others found solid silicate particles in the central portion of snow crystals. Since then extensive studies have been conducted to 
examine the threshold temperatures of dust for ice nucleation. But not until recently have comprehensive measurements of their nucleation rates been conducted. The work of Möhler et al. (2006) provided one of the most detailed information of ice nucleation, including the nucleation rates and corresponding environmental conditions of temperature, pressure, and saturation ratio. Although they measured ice nucleation on three types of dusts, we selected data for the Arizona test dust (ATD) and Saharan dust (SD) because of their sufficient number of data. According to the classical theory, our analysis requires the following thermodynamic data: nucleation rate, air temperature and pressure for freezing nucleation, then an additional "saturation ratio over ice" for deposition nucleation. Since one data point each for ATD and SD lacks the information of saturation ratio according to their Table 2, it was excluded from our analysis. In addition, two data points for ATD that were measured at the same temperature seem to be problematic for giving ill-behaved results, thus were not included either. Note that Archuleta et al. (2005) and Field et al. (2006) also measured ice nucleation on dusts, but they only provided the conditions required to activate a certain percentage of dust. These conditions pertain to the aforementioned concept of "threshold supersaturation" or "threshold temperature," which are not suitable for our purpose. From Table 2 and Fig. 7 in Field et al. (2006), we were able to get nucleation rates for the Asian dust (AD). Although some experiments suggest that both condensation-freezing and deposition nucleation occurs, we selected only those that have been identified as deposition mode from Fig. 6 of Field et al. (2006). Note that SD and $\mathrm{AD}$ are more representative of natural dust than ATD.

The above measurements were performed in the large cylindrical aerosol chamber (Aerosol Interaction and Dynamics in the Atmosphere, AIDA; volume $84 \mathrm{~m}^{3}$ ) that was used as a moderate expansion cloud chamber under different cloud conditions like temperature, cooling rate, and ice supersaturation. The number concentration of ice particles was measured by an Optical Particle Counter (PCS2000 and Welas, Palas GmbH, Germany), a Small Ice Detector (University of Hertfordshire, UK), and was retrieved also by Fourier Transform Infrared (FTIR) extinction spectra. The mean adiabatic cooling rates (close to the time of nucleation) for the experiments were $1-2 \mathrm{~K} \mathrm{~min}^{-1}$. Note that, due to heat flux from the wall, the air temperature in their experiment deviates somewhat from the adiabatic profile and approaches an almost constant steady state value after about 15 to $20 \mathrm{~min}$ at a constant rate of pressure change. The rate of ice activated at each temperature range was obtained from the ratio of concentration of activated particles to total particles divide by the specific time span. Hung et al. (2003) measured freezing nucleation on dust coated with ammonium sulfate solution. This latter data set is used not only to derive the similar thermodynamic parameters but also to examine the closure of surface energy calculation as will be discussed in Sect. 4.
Bacteria are considered a major type of ice-nucleating bioaerosols because of their ubiquity and efficient ice nucleating capability. Their freezing activity appears associated with the cell structure (Maki et al., 1974), and more precisely due to unique proteins that act as nucleation catalyst (Ruggles et al., 1993). Decaying plant leaves were also found to act as IN, but the ice nucleation was identified to be of bacterial origin. In fact, some plant frost injury has been shown to involve an interaction of certain leaf-surface bacteria (Lindow, 1983). Worldwide availability of such nuclei was established by finding ice-forming nuclei in plant litters collected in different climatic zones (Schnell and Vali, 1973). The subsequent studies of Vali et al. (1976), Yankofsky et al. (1981), Levin et al. (1987), and Hazra et al. (2004) showed that such biogenic IN might be released from the earth's surface to the atmosphere and initiate significant ice formation at temperatures as high as $-2^{\circ} \mathrm{C}$, even more effective than silver iodide which is an artificial IN commonly used for cloud seeding. In this study we took the nucleation data for two types of bacteria (Erwinia herbicola and Pseudomonas syringae) from Yankofsky et al. (1981) and one (Pseudomonas aeruginosa) from Hazra et al. (2004). E. herbicola and P. syringae are common plant-pathogenic bacteria that can infect a wide range of plant species, whereas $P$. aeruginosa not only infects plants but also animals and humans. But the above studies considered only immersion freezing nucleation, and we were not able to find data for deposition nucleation on bacteria.

Freezing nucleus activity of $P$. syringae and $E$. herbicola (Yankofsky et al., 1981) of drops containing bacteria were determined in the drop freezing spectrometer. Some of these experiments were performed with the drops held for $2 \mathrm{~min}$ at fixed temperatures below $0^{\circ} \mathrm{C}$. The ice or water saturations were not recorded in these experiments. Nucleation activity of $P$. aeruginosa (Hazra et al., 2004) was conducted in a walk-in cold chamber at water saturation and at each temperature formvar coated slides were placed for $2 \mathrm{~min}$ to collect ice crystals.

Pollen is another category of bio-aerosols that may spread in large quantities and over wide ranges. Their surfaces contain active sites that enable them to take up water effectively. While there have been some investigations on the hygroscopic characteristics of pollens (Durham, 1941; Harrington and Metzger, 1963; Dingle, 1966), much less is known about their role as IN than about bacteria. Not until recently did Diehl et al. $(2001,2002)$ perform a series of measurements on ice nucleation from various kinds of pollens. They found that pollens initiate ice nucleation not via the deposition mode but by immersion freezing or condensationfreezing within the investigated temperature and ice supersaturation ranges. Von Blohn et al. (2005) extended the study by including more pollen types. From Diehl et al. (2001) we took nucleation data for four kinds of pollens: birch, oak, grass, and pine. As only the fractions of nucleation were provided, we again obtain their experiment time of $1 \mathrm{~min}$ by personal communication. In addition, we used our own 
Table 1. Information regarding to the species of ice nuclei, including the mode of nucleation, the assigned sizes, the size range, as well as the data sources of nucleation rate and particle size.

\begin{tabular}{|c|c|c|c|c|c|c|}
\hline \multirow{2}{*}{ category } & \multirow{2}{*}{ sub-species } & \multirow{2}{*}{ nucleation mode } & \multicolumn{2}{|c|}{ diameter in $\mu \mathrm{m}$} & \multicolumn{2}{|c|}{ reference } \\
\hline & & & assigned & range & nucleation data & size \\
\hline soot & - & freezing & 0.1 & $0.08 \sim 0.12$ & $\mathrm{a}$ & $\mathrm{a}$ \\
\hline \multirow{3}{*}{ bacteria } & E. herbicola & freezing & 1. & $0.5 \sim 2.0$ & $\mathrm{~b}$ & $\mathrm{~b}, \mathrm{i}^{*}, \mathrm{j}^{*}, \mathrm{~m}$ \\
\hline & P. syringae & freezing & 1. & $0.5 \sim 2$ & $\mathrm{~b}$ & $\mathrm{~b}, \mathrm{k}^{*}, \mathrm{~m}$ \\
\hline & P. aeruginosa & freezing & 1. & $0.5 \sim 3.0$ & $\mathrm{c}$ & $\mathrm{c}, \mathrm{l}^{*}, \mathrm{~m}$ \\
\hline \multirow{6}{*}{ pollen } & birch & freezing & 25. & - & $\mathrm{d}$ & $\mathrm{d}$ \\
\hline & oak & freezing & 25. & $20 \sim 35$ & $\mathrm{~d}$ & $\mathrm{~d}$ \\
\hline & grass & freezing & 35. & $30 \sim 45$ & d & $\mathrm{d}, \mathrm{n}$ \\
\hline & pine & freezing & 50. & $35 \sim 70$ & d & $\mathrm{d}$ \\
\hline & eucalyptus sp. & freezing & 45. & $10 \sim 80$ & d & $\mathrm{e}^{*}$ \\
\hline & China rose & freezing & 45. & $10 \sim 80$ & e & $\mathrm{e}^{*}$ \\
\hline \multirow{4}{*}{ dust } & Hematite/corundum & freezing & - & $0.05 \sim 0.25$ & $\mathrm{f}$ & $\mathrm{f}$ \\
\hline & Asian dust & deposition & 0.4 & $0.1 \sim 2$ & $\mathrm{~g}$ & $\mathrm{~g}, \mathrm{~h}$ \\
\hline & Saharan dust & deposition & 0.35 & $0.1 \sim 2$ & $\mathrm{~g}$ & $\mathrm{~g}, \mathrm{~h}$ \\
\hline & Arizona test dust & deposition & 0.35 & $0.1 \sim 2$ & $\mathrm{~h}$ & $\mathrm{f}, \mathrm{h}$ \\
\hline
\end{tabular}

* electron microscopy images

a. DeMott (1990); b. Yankofsky et al. (1981); c. Hazra et al. (2004); d. Diehl et al. (2001); e. this study; f. Hung et al. (2003); g. Field et al. (2006); h. Möhler et al. (2006); i. Brandl et al. (2001); j. Miller et al. (1981); k. Mansvelt and Hattingh (1989); 1. Plotkowski et al. (1991); m. Levin et al. (1987); n. Bragg (1969).

datasets for the freezing nucleation rates for the pollens of eucalyptus and China Rose. The experiment was carried out in the same way as the experiment on Pseudomonas aeruginosa that mentioned above (for more details see Hazra et al., 2004). Condensation freezing efficiency of different pollens (Deihl et al., 2001) was measured inside the walk-in cold chamber where glass flask having diameter of $30 \mathrm{~cm}$ was installed. At supersaturation with respect to water pollen grains were scattered at equilibrium temperature for a short period (nearly $1 \mathrm{~min}$ ) and activated grains fell down onto a soap film.

When Kumai (1951) and others analyzed the nucleation center of snow crystals, they also found that some of the cores were composed of combustion products such as soot. Subsequent evidence of soot as ice nuclei was suggested by Hobbs and Locatelli (1969) as well as Langer (1973) who observed a significant increase of IN downwind of burning forest or sugarcane fields. Similar mechanism was proposed by Ström and Ohlsson (1998) who found that cirrus ice crystals in a region of heavy air traffic often contain soot-like particles. In a laboratory experiment, Gorbunov et al. (2001) showed that soot surface contains chemical groups which can form hydrogen bonds with water molecules, thus enhancing ice nucleation. However, in contrast to the aforementioned IN species, soot particles can only initiate ice nucleation at rather low temperatures, as pointed out by Hallett et al. (1986), DeMott (1990) and Dymarska et al. (2006). In the latter study, ice nucleation on soot particles never occurred at temperatures above 248 K. Both DeMott (1990) and Dymarska et al. (2006) showed that soot particles initiate ice formation almost exclusively via the freezing nucleation mode. In the present study we took the nucleation fraction data of DeMott (1990), the one that provided sufficient information. For this experimental data, soot particles were generated using simple oxygen-deficient acetylene burner and injected into the Colorado State University dynamic cloud chamber (volume $1.2 \mathrm{~m}^{3}$ ) to see its nucleation activity during expansion to $-40^{\circ} \mathrm{C}$ with adiabatic cooling rate of $1^{\circ} \mathrm{C} \mathrm{min}^{-1}$. The freezing rate per unit volume was calculated between $-26^{\circ} \mathrm{C}$ and $-34^{\circ} \mathrm{C}$. Ice crystals were detected by extinction in a laser-based detection device (DeMott and Rogers, 1990). Most crystals formed by immersion freezing mode. Cumulative fraction nucleated as a function of temperature was presented in this experiment.

In addition to the nucleation rates and ambient conditions, the sizes of these IN are also important to our analysis of the thermodynamic parameters for ice nucleation. Some experiments provide exact information of particle sizes and other relevant experimental data, while others lack this type of information. For the missing information we resort to other literatures to obtain estimations. Uncertainties of such estimations will be discussed later. Table 1 gives a summary of the types of IN, as well as their mode of nucleation, 
representative size and actual size range that will be used for analysis later.

\subsection{Classical nucleation theory}

Classical nucleation theory is straightforward, but is repeated here for discussion purpose. The rate of heterogeneous nucleation per particle is proportional to particle's total surface area and the rate of surface nucleation $J_{s}$; whereas $J_{S}$ is determined by the number of critical embryo per unit area $n^{*}$, and the rate at which the critical embryo may gain one molecule through interaction with the parent phase $A_{1}$ to overcome the nucleation energy barrier (Mason, 1971, p. 474-478; Hagen et al., 1981; Pruppacher and Klett, 1997, p. 303):

$J=4 \pi r_{N}^{2} J_{s}=4 \pi r_{N}^{2} A_{1} n^{*} Z$,

where $r_{N}$ is the radius of ice nuclei. To account for the depletion of embryo population due to germ production, the nucleation rate should be modified by the Zeldovich factor $Z$ as shown in the above equation (cf. Pruppacher and Klett, 1997, p. 202; Vehkamäki et al., 2007):

$Z=\frac{1}{n_{g}} \cdot \sqrt{\frac{\Delta g_{g}}{3 \pi k T}}$,

where $n_{g}$ is the number of water molecules in the ice germ, $\Delta g_{g}$ represents the energy of critical embryo (germ) formation, $k$ is the Boltzmann constant, and $T$ is temperature. The number of water molecules in an ice germ can be easily defined as $n_{g}=4 \pi r_{g}^{3} /\left(3 v_{w}\right)$, where $r_{g}$ is the radius of the embryo germ and $v_{w}$ is the volume of a water molecule. In Eq. (1), the number of critical ice germ, $n^{*}$, which are formed by stochastic aggregation of molecules, can be approximated by the Boltzmann's expression:

$n^{*}=n_{1} \cdot \exp \left(\frac{-\Delta g_{g}}{k T}\right)$,

where $n_{1}$ is the number of single molecules in contact with unit area of the substrate. The stochastic or statistical concept contained in the above expression is the core of the classical theory, which is thus often referred to as the statistical model of nucleation. Equation (1) can be applied to ice nucleation from both the vapor phase (deposition nucleation) and liquid phase (freezing nucleation). The parameters $A_{1}, n_{1}, \Delta g_{g}$ and $r_{g}$ are specific to the mode of nucleation, and can be derived according to classical nucleation theory as given separately below.

\subsubsection{Deposition nucleation}

For deposition nucleation, the molecule flux $A_{1}$ in Eq. (1) is determined from the kinetic theory (Mason 1971, p. 474):

$A_{1}=4 \pi r_{g}^{2} \frac{e}{\sqrt{2 \pi m_{w} k T}}$ where $e$ is the vapor pressure, $m_{w}$ is the mass of a water molecule, and the germ size $r_{g}$ can be expressed as:

$r_{g}=\frac{2 v_{w} \sigma_{i} / v}{\Delta g_{b}}$,

in which $\sigma_{i / v}$ is the surface tension between ice and vapor, $\Delta g_{b}=k T \ln S_{i}$ is the bulk free energy (also called the chemical potential) of phase change, and $S_{i}$ is saturation ratio with respect to ice. The second parameter, $n_{1}$, in $J_{s}$ for the deposition process can be determined under the assumption of a steady state adsorption-desorption fluxes (Pruppacher and Klett 1997, p. 300):

$n_{1}=\frac{e}{v_{s} \sqrt{2 \pi m_{w} k T}} \exp \left(\frac{-\Delta g_{d}}{k T}\right)$,

where $v_{s}$ is the frequency of vibration of water vapor molecule adsorbed on solid substrate, $\Delta g_{d}$ is the energy of desorption. According to classical nucleation theory, the energy of germ (critical embryo) formation for heterogeneous nucleation $\Delta g_{g}$ (Eqs. (2) and (3)) is simply the homogeneous nucleation energy of germ formation $\Delta g_{g}^{\circ}$, modified by a geometrical factor $f$ (i.e. $\Delta g_{g}=\Delta g_{g}^{\circ} \cdot f$ ), where

$\Delta g_{g}^{\circ}=\frac{16 \pi v_{w}^{2} \sigma_{i / v}^{3}}{3 \Delta g_{b}^{2}}=\frac{4 \pi}{3} \sigma_{i / v} \cdot r_{g}^{2}$.

The geometric factor for ice germ formation on a planar surface is a function of the contact angle only:

$f=f(m)=\frac{(2+m)(1-m)^{2}}{4}$,

where $m=\cos (\theta)$ is called the wetting coefficient, $\theta$ is the contact angle of ice germ on the substrate. But on a curved surface, $f$ is also a function of the germ size (cf. Fletcher, 1958; Pruppacher and Klett, 1997, p. 302; Liu, 1999):

$f=f(m, q)=\frac{1}{2}\left\{1+\left(\frac{1-m q}{\phi}\right)^{3}+q^{3}\left[2-3\left(\frac{q-m}{\phi}\right)+\left(\frac{q-m}{\phi}\right)^{3}\right]+3 m q^{2}\left(\frac{q-m}{\phi}-1\right)\right\}$

where $\phi \equiv \sqrt{1-2 m q+q^{2}}$, and $q \equiv r_{N} / r_{g}$. When $r_{N}$ approaches zero or the contact angle is at its extreme $(\theta=\pi)$, the geometric factor $f$ approaches unity so the condition reduces to homogeneous nucleation. For $r_{N}$ approaches infinity, $f$ should reduce to Eq. (8) (i.e., for a planar surface).

The above description is the simplest and most fundamental notion for viewing heterogeneous nucleation as derived from the phenomenon of wettability and its manifestation in the contact angle. On an insoluble substrate, the germ of the new phase is assumed to be a spherical cap with the contact angle characterizing the relationship between the three interfacial energies involved. While this model is based on the formation of a liquid germ from the vapor, it is also adopted as the basis for heterogeneous nucleation of solids from a gaseous of aqueous parent phase. Ice germs may have crystalline structure with hexagonal shape or prismatic shape (cf. Hobbs, 1974, p. 473), so it is difficult to define ice germ's 
contact angle. But it must also be realized that ice germs may actually be so small that descriptions in terms of simple geometric forms may not be appropriate either. In addition, nucleation takes place on specific locations (sites) on the substrate surfaces, which is a clear indication of the dominant roles of specific surface features such as steps or dislocations. But even so, the statistical model described above would still work if the preferred sites for embryo growth can be considered equal and randomly distributed. There is very little theoretical guidance on how to formulate descriptions of the interaction energy between such sites and the germs of ice. In any case, the contact angle for ice germs discussed here should be considered as an "apparent parameter", and further discussion on this will follow.

\subsubsection{Freezing nucleation}

For freezing nucleation, Turnbull and Fischer (1949) defined the molecule flux $A_{1}$ as:

$A_{1}=\frac{k T}{h} \exp \left(\frac{-\Delta g_{a}}{k T}\right)$

where $h$ is the Plank's constant, and $\Delta g_{a}$ is the activation energy for the transfer of a water molecule across the waterice boundary. Other variables that need to be re-defined when we discuss homogeneous freezing include the energy of germ formation $\Delta g_{g}$ and germ size $r_{g}$ in Eqs. (5) and (7), in which $\sigma_{i / v}$ should be replaced by $\sigma_{i / w}$ (surface tension between ice and liquid water) to reflect a change of the parent phase. Likewise, the bulk free energy of phase change now becomes $\Delta g_{b}=k T \ln \left(e_{s w} / e_{s i}\right)$, where $e_{s w}$ and $e_{s i}$ are the saturation vapor pressure over water and ice, respectively. Note that for the freezing of solution, the parameter $e_{s w}$ in $\Delta g_{b}$ should be modified by the water activity of the solution (cf. Mason, 1971, p. 491; Heymsfield and Sabin, 1989). In contrast to that for deposition nucleation, the parameter $n_{1}$ for freezing nucleation does not vary significantly because the concentration of molecules in a liquid parent-phase is rather constant. For a water density of $1 \mathrm{~g} \mathrm{~cm}^{-3}$, one can easily calculate that $n_{1}=1.0 \times 10^{19} \mathrm{~m}^{-2}$, which is the same as that given in Fletcher (1962) but much larger than the $5.3 \times 10^{16} \mathrm{~m}^{-2}$ given by Eadie (1971; also see Pruppacher and Klett 1997, p. 206). The geometric factor $f$ maintains the same form as in Eqs. (9) and (10) for both nucleation modes. Note that for the discussions below, the term "freezing nucleation" is referred to immersion freezing only and not to condensation freezing for which the parameterization method will be discussed in Sect. 4.3.

\section{Linearization analyses of classical theory}

The nucleation rate given in Eq. (1) consists of two groups of parameters; (A) ambient variables such as air temperature (and temperature dependent variables), vapor pressure and ice supersaturation; (B) particle variables, including particle size $r_{N}$, the activation energy ( $\Delta g_{d}$ for deposition nucleation or $\Delta g_{a}$ for freezing nucleation), and the contact angle $\theta$ (or the wetting coefficient $m$ ). Existing laboratory studies provided the nucleation rates and the corresponding environment variables of group (A). But the particle parameters of group (B), particularly the activation energy and contact angle, are virtually unknown for common atmospheric IN. Our main task is to derive these parameters from laboratory measurements.

The rate equation for both nucleation modes actually can be expressed in the same form. One can see this by first rearranging Eq. (1) into:

$J=A^{\prime} \cdot r_{N}^{2} \cdot \sqrt{f} \cdot \exp \left(\frac{-\Delta g^{\#}-\Delta g_{g}}{k T}\right)$,

where $A^{\prime}$ depends on ambient parameters only; $\Delta g^{\#}$ is either $\Delta g_{d}$ in Eq. (6) or $\Delta g_{a}$ in Eq. (10), and they will be generally termed the activation energy for future discussion. For deposition nucleation, $\Delta g^{\#}=\Delta g_{d}$ and

$$
A^{\prime}=\frac{2 \pi\left(r_{g} e\right)^{2}}{m_{w} k T v_{s} n_{g} \sqrt{3 \pi}} \cdot \sqrt{\frac{\Delta g_{g}^{\circ}}{k T}}=\frac{e^{2} v_{w}}{m_{w} k T v_{s}} \cdot \sqrt{\frac{\sigma_{i / v}}{k T}} .
$$

For freezing nucleation, $\Delta g^{\#}=\Delta g_{a}$ and

$A^{\prime}=4 \pi \cdot \frac{1}{n_{g}} \cdot \sqrt{\frac{\Delta g_{g}^{\circ}}{3 \pi k T}} \cdot \frac{k T}{h} \cdot n_{1}$

The rate Eq. (11) contains three parameters that are properties of the ice nuclei: particle size $r_{N}$, activation energy $\Delta g^{\#}$, and wetting coefficient $m$ (or contact angle) which are within the term $f$. With a few sets of nucleation rate and ambient condition data that measured in the laboratory, it is possible to derive these particle parameters from Eq. (11) particularly when the particle size is known. In the following, we intent to linearize Eq. (11) and perform data fitting to derive the two parameters $\Delta g^{\#}$ and $m$. Note that one must be careful in the physical interpretation of these key parameters. Due to various uncertainties that will be discussed later, they should be regarded as "apparent" thermodynamic parameters emerging from the analyses.

\subsection{Initial analysis}

Recall from Eq. (9) that the geometric factor $f$ is a complicated function of nuclei size, contact angle, and air properties. But under typical conditions, its primary dependent variable is the contact angle. So we shall first assume it is a constant, taking the form of Eq. (8), and extend the analysis later for an exact $f$. By taking the logarithmic of Eq. (11), we have

$\underbrace{k T\left(\ln J-\ln A^{\prime}-\ln r_{N}^{2}\right)}_{y}=\underbrace{k T \ln \sqrt{f}-\Delta g^{\#}}_{a}-\underbrace{f}_{b} \cdot \underbrace{\Delta g_{g}^{\circ},}_{x}$ 
Table 2. Results of IN properties derived from the initial analysis. Units are $10^{-20} \mathrm{~J}$ for $\Delta g^{\#}$, and $\mu \mathrm{m}$ for $r_{N}$. The coefficient of determination, $R^{2}$, for the final fitting is also listed.

\begin{tabular}{lllccccc}
\hline \multirow{2}{*}{ Species } & \multirow{2}{*}{ Assigned } & Eq. 14a & \multicolumn{2}{c}{ Eq. 14b } & \multicolumn{2}{c}{ Eq. 14c } & $R^{2}$ \\
& $r_{N}$ & $f$ & $\Delta g^{\#}$ & $r_{N}$ & $f$ & $r_{N}$ & \\
\hline Soot & 0.05 & 0.0693 & 12.75 & 0.06 & 0.0686 & 0.06 & 0.994 \\
E. herbicola & 0.5 & 0.0025 & 13.16 & 0.82 & 0.00249 & 0.82 & 0.990 \\
P. syringae & 0.5 & 0.000719 & 13.42 & 0.90 & 0.000706 & 0.88 & 0.996 \\
P. aeruginosa & 0.5 & 0.00024 & 13.32 & 1.11 & 0.000225 & 1.11 & 0.940 \\
Grass & 17.5 & 0.0065 & 15.71 & 17.66 & 0.0063 & 17.34 & 0.951 \\
Oak & 12.5 & 0.0075 & 15.21 & 12.5 & 0.0073 & 12.21 & 0.989 \\
Pine & 25 & 0.0029 & 15.71 & 25.07 & 0.0028 & 24.39 & 0.985 \\
Birch & 12.5 & 0.0052 & 15.10 & 12.21 & 0.0050 & 11.79 & 0.934 \\
Eucalyptus & 22.5 & 0.0058 & 15.46 & 23.1 & 0.0057 & 22.9 & 0.990 \\
China rose & 22.5 & 0.0072 & 15.41 & 20.1 & 0.0071 & 19.87 & 0.992 \\
AD & 0.2 & 0.000091 & 3.72 & 0.46 & 0.00083 & 0.42 & 0.916 \\
SD & 0.175 & 0.0000087 & 6.55 & 2.75 & 0.0000086 & 2.74 & 0.996 \\
ATD & 0.175 & 0.000038 & 6.45 & 4.54 & 0.000038 & 4.50 & 0.979 \\
\hline
\end{tabular}

This formula is arranged in such a way that $x$ and $y$ can be directly determined from the experimental data, whereas the particle-related parameters are kept in the coefficients $a$ and $b$. Therefore, by fitting the experimental data with the linear equation $y=a-b x$, we are able to derive the coefficients $a$ and $b$, and from which we can obtain the particle parameters. For example, using Eq. (14a), the geometric factor $f$ can be derived immediately as it is exactly the coefficient $b$. However, the coefficient $a$ contains air temperature and thus is not truly a constant, and the uncertainties contained in it will inevitably pass to the value of $b$. This also means that we are not able to obtain directly the second parameter, the activation energy $\Delta g^{\#}$, from the coefficient $a$.

To derive the value of the activation energy, we can take a variation of Eq. (14a) as:

$\underbrace{k T\left(\ln J-\ln A^{\prime}-\ln \sqrt{f}\right)+f \cdot \Delta g_{g}^{\circ}}_{y}=\underbrace{-\Delta g^{\#}}_{a}+\underbrace{\ln r_{N}^{2}}_{-b} \cdot \underbrace{k T}_{x}$.

In this formula, we applied into $y$ the previously derived coefficient $f$ as an initial guess. This gives us not only the value of $\Delta g^{\#}$ but also the nuclei size which we use to indicate the robustness of our method. Of course, all values derived so far still contain the previously mentioned uncertainties. Some of the uncertainties can be minimized by introducing another variation of Eq. (14a):

$\underbrace{\ln J-\ln A^{\prime}+\Delta g^{\#} / k T}_{y}=\underbrace{\ln \left(r_{N}^{2} \sqrt{f}\right)}_{a}-\underbrace{f}_{b} \cdot \underbrace{\Delta g_{g}^{\circ} / k T}_{x}$.

Here, we can apply the $\Delta g^{\#}$ obtained from Eq. (14b) into $y$ to re-derive $f$. Further calculation by iteration between the two procedures (Eqs. (14b) and (14c)) has been tried, but the results do not converge. But this is not a problem because we only want to obtain an initial estimation and get a sense of the order of magnitude of the desired parameters. More detailed analysis will be performed in the next section.
Table 2 shows the results obtained by a simple iteration from Eqs. (14a) to (14c) for the species shown in Table 1. One can see that the two values of $f$ are quite close to each other, but the calculated $r_{N}$ may differ significantly from the originally assigned values for some IN species. The discrepancy in $r_{N}$ arises either from the uncertainties in the formulation procedure or due to the assumption of constant $f$. In the next section we will try to minimize both.

\subsection{Refined geometric factor}

In the above analysis, we have assumed that $f$ takes the form of Eq. (8) and is independent of the ambient parameters. But in fact $f$ is also a function of particle size $r_{N}$ and the germ size $r_{g}$ as given in Eq. (9). For a more accurate analysis we need to consider these dependences. But the original form of Eq. (9) is too complicated to be decomposed for the analysis done in the previous section. This problem can be circumvented by fitting Eq. (9) into either of the following two equations, which separate out particle size (contained in $q$ ) and contact angle:

$$
\begin{aligned}
& \ln f \approx c_{1}+c_{2} \cdot \ln (1-m)+c_{3} / q . \\
& \ln f \approx c_{4}+c_{5} \cdot \ln (1-m)+c_{6} \cdot \ln q,
\end{aligned}
$$

The coefficients of the above equations are given in Table 3 for the species of IN considered in this study under appropriate ranges of $q$ and $\theta$. The coefficients of determination $\left(R^{2}\right)$ for these fittings are all greater than 0.98, and their maximum errors are quite small except for ATD and hematite.

By applying Eq. (15a) into Eqs. (14a) and (14b), we obtained two variations of fitting on the nucleation rate formula as done in the previous section but without assuming $f$ as a constant: 
Table 3. Coefficients of the fitting formulas in Eq. (15) for various ice nuclei and under different ranges of germ size ratio $q$, contact angle $\theta$ and the corresponding wetting coefficient. Also given is the maximum error from each approximation formula.

\begin{tabular}{|c|c|c|c|c|c|c|c|}
\hline & bacteria & soot & pollens & Asian dust & Saharan dust & ATD & Hematite \\
\hline$q$ & $10 \sim 363$ & $9 \sim 140$ & $>250$ & $10 \sim 200$ & $5 \sim 110$ & $2.4 \sim 44$ & $40 \sim 400$ \\
\hline$m$ & $0.940 \sim 0.997$ & $0.602 \sim 0.875$ & $0.866 \sim 0.971$ & $0.940 \sim 0.970$ & $0.961 \sim 0.990$ & $0.985 \sim 0.996$ & $-0.866 \sim 0.450$ \\
\hline$\theta$ & $4 \sim 20$ & $29 \sim 53$ & $14 \sim 30$ & $14 \sim 20$ & $8 \sim 16$ & $5 \sim 10$ & $63 \sim 150$ \\
\hline$c_{1}$ & -0.3541568 & -0.5411955 & -0.3962579 & -0.3598818 & -0.3353619 & -0.3497709 & -0.7352132 \\
\hline$c_{2}$ & 1.983928 & 1.879918 & 1.968181 & 1.982032 & 1.990979 & 1.994605 & 1.315406 \\
\hline$c_{3}$ & 2.019456 & 1.607947 & 1.858932 & 2.025390 & 2.175539 & 2.527253 & 0.5413986 \\
\hline$r^{2}$ & 0.9999 & 0.9999 & 0.9999 & 0.9999 & 0.9999 & 0.9994 & 0.9853 \\
\hline max. error & $3.1 \%$ & $3.9 \%$ & $1.46 \%$ & $0.24 \%$ & $0.8 \%$ & $3.1 \%$ & $12 \%$ \\
\hline$c_{4}$ & -0.08853648 & -0.27167433 & -0.3748873 & -0.06841440 & 0.1725698 & 0.7220012 & -0.7064756 \\
\hline$c_{5}$ & 1.983878 & 1.879725 & 1.968181 & 1.983733 & 1.990979 & 1.994605 & 1.3154064 \\
\hline$c_{6}$ & -0.05019220 & -0.05747428 & -0.002749135 & -0.05734672 & -0.1147096 & -0.3046048 & -0.00478509 \\
\hline$r^{2}$ & 0.9990 & 0.9987 & 0.9999 & 0.9976 & 0.9963 & 0.9794 & 0.9853 \\
\hline max. error & $6.2 \%$ & $5.4 \%$ & $1.43 \%$ & $2.6 \%$ & $6.2 \%$ & $15 \%$ & $11 \%$ \\
\hline
\end{tabular}

$\underbrace{k T\left\{\ln \left(J / A^{\prime} / r_{N}^{2}\right)-0.5 \cdot\left(c_{1}+c_{3} \cdot r_{g} / r_{N}\right)-0.5 \cdot c_{2} \cdot \ln (1-m)\right\}}_{y}$
$=\underbrace{-\Delta g^{\#}}_{a}-\underbrace{(1-m)^{c_{2}}}_{b} \cdot \underbrace{\Delta g_{g}^{\mathrm{o}} \cdot \exp \left(c_{1}+c_{3} \cdot r_{g} / r_{N}\right)}_{x}$

$\underbrace{\ln \left(J / A^{\prime} / r_{N}^{2}\right)+\Delta g^{\#} /(k T)-0.5 \cdot\left(c_{1}+c_{3} \cdot r_{g} / r_{N}\right)}_{y}$

$=\underbrace{0.5 \cdot c_{2} \cdot \ln (1-m)}_{a}-\underbrace{(1-m)^{c_{2}}}_{b} \cdot \underbrace{\Delta g^{\circ} /(k T) \cdot \exp \left(c_{1}+c_{3} \cdot r_{g} / r_{N}\right)}_{x}$

In both equations, the coefficients $a$ and $b$ no longer contain ambient parameters but are purely functions of the particle parameters $\Delta g^{\#}$ (activation energy) and $m$ (cosine contact angle). However, the independent variable $y$ also contains these supposedly unknown parameters. So, we need an initial guess of either $m$ or $\Delta g^{\#}$ in order to solve Eqs. (16a) and (16b) iteratively. But now it is not necessary to go through a similar procedure as Eq. (14a) to get the initial guess because the results in Table 2 are already suffice for this purpose. The calculations converged quickly within three iterations after including the more accurate treatment of the factor $f$. Note that we also applied Eq. (15b) into Eq. (14a) to obtain a fitting formula in the form of:

$\underbrace{\ln \left(J / A^{\prime}\right)+\Delta g^{\#} /(k T)-0.5 \cdot\left(c_{4}-c_{5} \ln r_{g}\right)}_{y}$
$=\underbrace{\ln r_{N}^{2}+0.5 \cdot\left[c_{5} \cdot \ln (1-m)+c_{6} \cdot \ln r_{N}\right]}_{b}$
$-\underbrace{(1-m)^{c_{5}} \cdot r_{N}^{c_{6}}}_{a} \cdot \underbrace{\Delta g^{\circ} /(k T) \cdot \exp \left(c_{4}\right) \cdot r_{g}^{-c_{6}}}_{x}$
This fitting formula, when used in conjunction with either Eq. (16a) or Eq. (16b), gives very similar results as before. Furthermore, it also gives the nuclei size which we use to check the self-consistency. The refined results are given in Table 4. We can see that the values of $\Delta g^{\#}$ differ slightly from those in Table 2 for all species except dusts, for which the deviation may reach $28 \%$ (ATD). The differences in $m$ behaved similarly, with the largest discrepancy of about $50 \%$ occurr in the species SD. These large errors signify the importance of a more detailed treatment of the factor $f$. Note that the calculated $r_{N}$ are now very close to their assigned values, and this is a good indication of self-consistency of our method.

\subsection{Curvature and solute effects on surface tension}

When extending our analysis on the data of Hung et al. (2003) we realized that our previous treatment was not comprehensive enough. Their experiment considered the freezing of ammonium sulfate solution with mineral dust as the nucleation center. We therefore included the solute effect on $e_{s w}$ contained in the term $\Delta g_{g}^{\circ}$ by multiplying it with the water activity using the empirical formula in Chen (1994). Note that in Hung et al. (2003) the measurements for hematite $\left(\mathrm{Fe}_{2} \mathrm{O}_{3}\right)$ were done in a rather narrow temperature range, but their different dust sizes give extra variability that benefits our analysis. However, for corundum $\left(\mathrm{Al}_{2} \mathrm{O}_{3}\right)$ there is only one measurement temperature, which makes the fitting analysis difficult and no reasonable result was obtained. Our calculation shows that the contact angle of ice germ on hematite ranges from $106.2^{\circ}$ at low solute concentration (mole fraction $\chi=0.03$ ) to $74.4^{\circ}$ at high solute concentration $(\chi=0.13)$. Similar to our approach, Hung et al. (2003) applied measurement data into classical theory to 
Table 4. Results of IN properties derived from the refined analysis. Units are $10^{-20} \mathrm{~J}$ for $\Delta g^{\#}$, degree for $\theta$, and $\mu \mathrm{m}$ for $r_{N}$. Note that $f^{*}$ is calculated from $m$ using Eq. (9) for comparison with the rough estimates given in Table 2. The coefficient of determination, $R^{2}$, for each fitting is also listed.

\begin{tabular}{llllllll}
\hline Species & $\Delta g^{\#} m$ & $f^{*}$ & $\theta$ & $\begin{array}{l}\text { Assigned } \\
r_{N}\end{array}$ & $\begin{array}{l}\text { Derived } \\
r_{N}\end{array}$ & $R^{2}$ \\
\hline Soot & 12.6 & 0.691 & $6.42 \mathrm{E}-2$ & 46.3 & 0.05 & 0.05 & 0.993 \\
E. herbicola & 12.8 & 0.943 & $2.39 \mathrm{E}-3$ & 19.4 & 0.5 & 0.5 & 0.990 \\
P. syringae & 13.0 & 0.969 & $7.04 \mathrm{E}-4$ & 14.3 & 0.5 & 0.5 & 0.996 \\
P. aeruginosa & 12.7 & 0.983 & $2.10 \mathrm{E}-4$ & 10.5 & 0.5 & 0.5 & 0.941 \\
Grass & 15.7 & 0.907 & $6.27 \mathrm{E}-3$ & 24.9 & 17.5 & 17.6 & 0.951 \\
Oak & 15.2 & 0.899 & $7.41 \mathrm{E}-3$ & 26.0 & 12.5 & 12.5 & 0.989 \\
Pine & 15.7 & 0.939 & $2.75 \mathrm{E}-3$ & 20.2 & 25.0 & 24.8 & 0.985 \\
Birch & 15.1 & 0.917 & $5.05 \mathrm{E}-3$ & 23.5 & 12.5 & 12.4 & 0.934 \\
Eucalyptus & 15.9 & 0.912 & $5.66 \mathrm{E}-3$ & 24.2 & 22.5 & 22.57 & 0.990 \\
China rose & 16.0 & 0.901 & $7.08 \mathrm{E}-3$ & 25.7 & 22.5 & 22.49 & 0.992 \\
AD & 3.31 & 0.991 & $6.47 \mathrm{E}-5$ & 7.82 & 0.20 & 0.204 & 0.919 \\
SD & 4.94 & 0.998 & $4.32 \mathrm{E}-6$ & 3.97 & 0.175 & 0.175 & 0.992 \\
ATD & 4.64 & 0.995 & $2.10 \mathrm{E}-5$ & 5.90 & 0.175 & 0.175 & 0.964 \\
\hline
\end{tabular}

find an optimum value of contact angle. However, they apparently neglected the Zeldovich factor in Eq. (1) as well as the activation energy term and other details that will be discussed later. The contact angles they obtained were $90^{\circ}$ or $97^{\circ}$, depending on the different criteria they set. Although the two calculations seem to be reasonably close to each other, these contact angles are significantly larger than for other types of freezing IN shown in Table 4. As will be discussed later, contact angle is the most important factor in determining the nucleation capability of IN. The large angles derived above would imply a poor nucleating capability of hematite that is even inferior to soot. Such a result seems to be at odds with the perceptions that mineral dusts typically have higher threshold temperature of nucleation than soot, and this prompted us to go back over our analysis.

The first missing factor that we found is the effect of solute on the surface tension of water, which strongly influences the germ formation energy and germ size. Unfortunately, no data exist for the surface tension between ice and water solution. We overcome this by applying the Antonoff's rule (Pruppacher and Klett, 1997, p. 160), which states that the surface tension between a solid and liquid $\left(\sigma_{i / l}\right)$ can be approximated by the difference between the surface tension of solid-air interface $\left(\sigma_{i / a}\right)$ and that of liquid-air interface $\left(\sigma_{l / a}\right)$ :

$\sigma_{i / l} \approx \sigma_{i / a}-\sigma_{l / a}$,

where the subscript " $l$ " represents a solution to contrast with the subscript " $w$ " that we used to for pure water. The values of $\sigma_{i / a}$ can be found in various literatures, whereas the value of $\sigma_{l / a}$ for the solutions of ammonia sulfate and several other solute species can be obtained from Chen (1994). As $\sigma_{l / a}$ increases with increasing ammonium sulfate concentration, surface tension between ice and solution $\left(\sigma_{l / a}\right)$ becomes lower under the presence of solute. Table 5 listed the calculated thermodynamic parameters with and without the
Table 5. Contact angle and activation energy calculated from the freezing nucleation data of Hung et al. (2003) with consideration of the solute effect and curvature effect on the surface tension. The conditions for surface tension include solute mole fraction $\chi$ and ice-germ size $r$, so $\sigma(0, \infty)$ means both effects are ignored, $\sigma(\chi, \infty)$ includes solute effect only, and $\sigma(\chi, r)$ considers both effects. Values were calculated from data for hematite at concentrations of $\chi=0.03$ and $\chi=0.13$. Units are $10^{-20} \mathrm{~J}$ for $\Delta g_{a}$ and degree for $\theta$.

\begin{tabular}{lrrrrrrr}
\hline \multicolumn{2}{l}{ Solute mole fraction $\chi$} & \multicolumn{3}{c}{0.03} & \multicolumn{3}{c}{0.13} \\
\hline & parameters & $m$ & $\theta$ & $\Delta g_{a}$ & $m$ & $\theta$ & $\Delta g_{a}$ \\
conditions & & & & & & \\
\hline$\sigma(0, \infty)$ & -0.279 & 106.2 & 13.3 & 0.269 & 74.4 & 14.1 \\
$\sigma(\chi, \infty)$ & -0.825 & 145.6 & 14.1 & -1.609 & - & 15.7 \\
$\sigma(\chi, r)$ & 0.351 & 69.4 & 9.9 & 0.448 & 63.4 & 14.3 \\
\hline
\end{tabular}

consideration of solute effect on surface tension. Unfortunately, under a solute mole fraction of $\chi=0.03$, the value of contact angle did not become smaller as hoped; whereas for the high solute concentration the wetting parameter $m$ even exceeded its lower bound of -1 , thus no contact angle can be obtained. So, the inclusion of solute effect leads us in the wrong direction.

Another important factor that may influence contact angle is the curvature adjustment of surface tension on ice germs. Tolman (1949) suggested that surface tension deviates from its bulk value when the particle is small, and the size adjustment follows $\sigma_{A / B}^{\prime}=\sigma_{A / B}^{\infty} \cdot \kappa$, where $\sigma^{\infty}$ is the bulk surface tension, and subscripts $A$ and $B$ represent the particle phase (here, ice germ) and the medium phase (here, water or air), respectively. The proportionality coefficient can be expressed as (also see Dufour and Defay, 1963, p. 61):

$\kappa=\frac{1}{1+2 \Gamma / r_{A}\left(\rho_{A}-\rho_{B}\right)} \equiv \frac{1}{1+2 \delta / r_{A}}$,

where $r_{A}$ is the particle size, $\rho$ is the density of the phase that indicated by its subscript, $\Gamma=1.55 \times 10^{-7} \mathrm{~kg} \mathrm{~m}^{-2}$ is the Gibbs surface adsorption, and

$\delta \equiv \Gamma /\left(\rho_{A}-\rho_{B}\right)$.

Note that this equation is equally applicable when the particle is of phase $B$, for which case a negative radius (curvature) is used for $r_{A}$ (i.e., treat it as a "bubble"). However, Eq. (18) gives unrealistic (negative) values of $\phi$ when $\left(\rho_{A^{-}}\right.$ $\rho_{B}$ ) is a small negative value (for the case of ice in water) and the particle size is small. Lu and Jiang (2004) provided a more general formula of curvature adjustment for nanocrystals in the gas phase:

$\kappa=\left(1-\frac{1}{4 r / \delta-1}\right) \cdot \exp \left(-\frac{2 E}{3 R T} \cdot \frac{1}{4 r / \delta-1}\right)$,

where $E$ is the bulk energy of phase transformation, and $R$ is the gas constant. We extended the use of their formula to other particle-medium systems by applying Eq. (19) for 
Table 6. Contact angle and activation energy for various IN species calculated with and without the curvature adjustment on surface tension. The values are for freezing nucleation except for the lowest three rows (AD, SD, and ATD), which pertain to deposition nucleation. Units are $10^{-20} \mathrm{~J}$ for $\Delta g^{\#}$ and degree for $\theta$.

\begin{tabular}{lrrrr}
\hline Curvature adjustment & \multicolumn{2}{c}{ no } & \multicolumn{2}{c}{ yes } \\
\hline \multicolumn{1}{c}{ parameter } & & $\Delta g^{\#}$ & $\theta(r)$ & $\Delta g^{\#}(r)$ \\
\hline soot & & & & \\
E. herbicola & 19.3 & 12.7 & 33.2 & 13.8 \\
$P$. syringae & 14.3 & 12.8 & 16.0 & 12.7 \\
P. aeruginosa & 10.5 & 12.7 & 12.5 & 12.8 \\
Grass & 24.9 & 15.7 & 5.30 & 12.2 \\
Oak & 26.0 & 15.3 & 20.6 & 15.5 \\
Pine & 20.2 & 15.7 & 17.8 & 15.1 \\
Birch & 23.5 & 15.1 & 18.8 & 15.0 \\
Eucalyptus & 24.2 & 15.9 & 18.4 & 15.7 \\
China rose & 25.7 & 16.0 & 20.3 & 15.8 \\
Hematite (0.03) & 145.6 & 14.1 & 69.4 & 9.90 \\
Hematite (0.13) & - & 15.7 & 63.4 & 14.3 \\
& & & & \\
AD & 7.82 & 3.31 & 8.10 & 1.82 \\
SD & 3.97 & 4.94 & 5.06 & 3.35 \\
ATD & 5.90 & 4.64 & 6.23 & 1.88 \\
\hline
\end{tabular}

the factor $\delta$, and found that it can be safely applied to all our situations. Besides influencing contact angle, curvature adjustment may also affect the germ size and energy of germ formation. From Eq. (5) we see that the germ size is directly proportional to the surface tension, so it should be modified accordingly with

$r_{g}^{\prime}=r_{g}^{\infty} \cdot \kappa$,

where $r_{g}^{\infty}$ is the bulk germ size given by Eq. (5). However, the factor $\kappa$ itself is a function of the germ size as can be seen in Eq. (20). Thus, $r_{g}^{\prime}$ and $\kappa$ need to be solved simultaneously (e.g. by iteration) from Eqs. (20) and (21).

From Eq. (20) one can see that the curvature adjustment depresses both the surface tension and size of ice germ that is embedded in air (e.g. deposition nucleation), but it enlarge them if the surrounding medium is water (e.g. freezing nucleation). As shown in Table 5, the resulting contact angle of $69.4^{\circ}$ at $\chi=0.03$ has shifted toward the desirable direction. Furthermore, the originally invalid value at $\chi=0.13$ now becomes a much more reasonable $63.4^{\circ}$. But these contact angles are still larger than that of soot. In the next section we will further elaborate the inconsistency of these values with other data.

In Table 6 we recalculated the contact angle and activation energy with the consideration of curvature adjustment for all species, and compare them with the old values shown in Table 4 . One can see that the curvature adjustment generally results in smaller contact angles for freezing nucleation and inversely so for deposition nucleation. As for the activation energies, the influence is quite prominent for the three dust species of deposition mode. Those values calculated with curvature adjustment can be regarded as the final result of this study.

Take Eqs. (14a) and (16a) as examples, we show the effects of linearization on the distribution of experimental data in Fig. 1. Figure 1a uses Eq. (14a) but neglects curvature adjustment; Fig. 1b and 1c are both from Eq. (16a) but without and with the curvature adjustment, respectively. From Fig. 1a one can see that Eq. (14a) already produced fairly good linearization. The curves are grouped naturally according to the general species types (i.e., bacteria, pollens or soot), and the distinct slope reflects the wetting parameter $f$ that is unique for each species. Results from Eq. (16a) in Fig. 1b are not much different in terms of the degree of linearization. But more importantly, these curves shift position to give more accurate values of contact angle and activation energy. The effect of curvature adjustment is shown Fig. 1c as opposed to Fig. 1b. One can see significant changes in the values of $x$ and $y$, resulting in substantial changes in the slope (mainly representing the contact angle) and intercept (mainly representing the activation energy). Note that the inclusion of curvature adjustment also slightly improved the $R^{2}$ of linear regression.

As can be realized from the equations of classical nucleation theory described in Sect. 2, the effect of curvature on surface tension will propagate to the germ size, the geometric coefficient $f$ and the energy of germ formation, and these are all key factors that determine the ice nucleation rate. The magnitude of influence also depends on the size of IN (through the factor $f$ ), causing the rate of surface nucleation $J_{s}$ in Eq. (1) to vary among IN of different sizes. So the curvature effect will complicate the interpretation of laboratory measurements using classical nucleation theory if a constant $J_{s}$ is assumed as done in some other studies.

\section{Discussions}

4.1 Relative significance of the activation energies and contact angles

Table 6 reveals the ice nucleating ability of various species. We can see that activation energy $\Delta g_{a}$ for freezing nucleation is the highest for pollens and slightly lower for bacteria and soot, but the differences between species and, particularly, between sub-species are not significant except for hematite. However, all the differences in $\Delta g^{\#}$ are too small to account for the vastly different nucleation capability among species. By examining Eq. (11) one may realize that $\Delta g^{\#}$ (either $\Delta g_{a}$ or $\Delta g_{d}$ ) is not a major factor in determining the nucleation rate because there is another stronger energy requirement for nucleation - the energy of germ formation $\Delta g_{g}$. Typically, $\Delta g_{g}$ are of the order of $10^{-16}$ to $10^{-18} \mathrm{~J}$, 
about two to three orders of magnitude larger than the activation energies. Only under very low temperature or high supersaturation does the activation energy become important. Another interesting contrast is that changes in the activation energy are relatively smaller for the freezing mode than for the deposition mode nucleation. This implies that the adsorption energy of vapor $\left(\Delta g_{d}\right)$ is sensitive to the composition or surface structure of the substrate, whereas the activation energy for the transfer of a water molecule across the water-ice boundary $\left(\Delta g_{a}\right)$ is not.

Let us see if the difference in contact angles may reflect the nucleation capability. Bacteria have significantly smaller contact angles (see Table 6), and this indeed reflects the fact that bacteria are better IN than the other freezing mode species as shown by the nucleation rate data or the so-called threshold temperature. Pseudomonas aeruginosa obviously is a more effective IN because of its smallest contact angle. Soot seems to have a lower (but only slightly) activation energy, yet it has a rather large contact angle. Exacerbated by its small size, soot apparently is not a very effective IN as can be seen from Eq. (1) for the size dependence of the nucleation rate. Pollens have the advantages of large sizes and relatively small contact angles, and thus they are relatively efficient ice nucleating agents. Among the six types of pollens, pine pollen has the smallest contact angle and largest size thus it should have better nucleation ability than other pollens, and this is confirmed by the experimental data. Hematite has the largest contact angle thus its freezing nucleation capability is even lower than soot.

For the three deposition-mode dust species, the contact angles are rather small, particularly for the SD and next to it the ATD, indicating mineral dusts are good nucleation agents, at least by deposition nucleation. We are not able to explain why the contact angle for freezing on a seemly similar mineral dust - hematite - is much larger, except that those hematite particles might not represent common mineral dust in the atmosphere.

\subsection{Verification of results}

There are very few direct measurements on the activation energies for the types of IN and nucleation conditions considered in this study, and essentially none for the contact angles. Therefore, it is difficult to get a direct comparison and verification for the results shown in Table 6 . However, by comparing with similar data one may get a sense of the correctness of our findings. We first look at $\Delta g_{a}$, the activation energy for the transfer of a water molecule across the waterice boundary.

Hagen et al. (1981) applied an approach similar to ours to analyze measurement data of nucleation rate, but for homogeneous freezing, to derive $\Delta g_{a}$. They obtained $8 \times 10^{-20} \mathrm{~J}$ (per $\mathrm{H}_{2} \mathrm{O}$ molecule) for $\Delta g_{a}$ at $-40^{\circ} \mathrm{C}$, and this value roughly increases by $0.3 \times 10^{-20}$ per degree $\mathrm{K}$ of temperature rise. If their calculation can be extrapolated to the
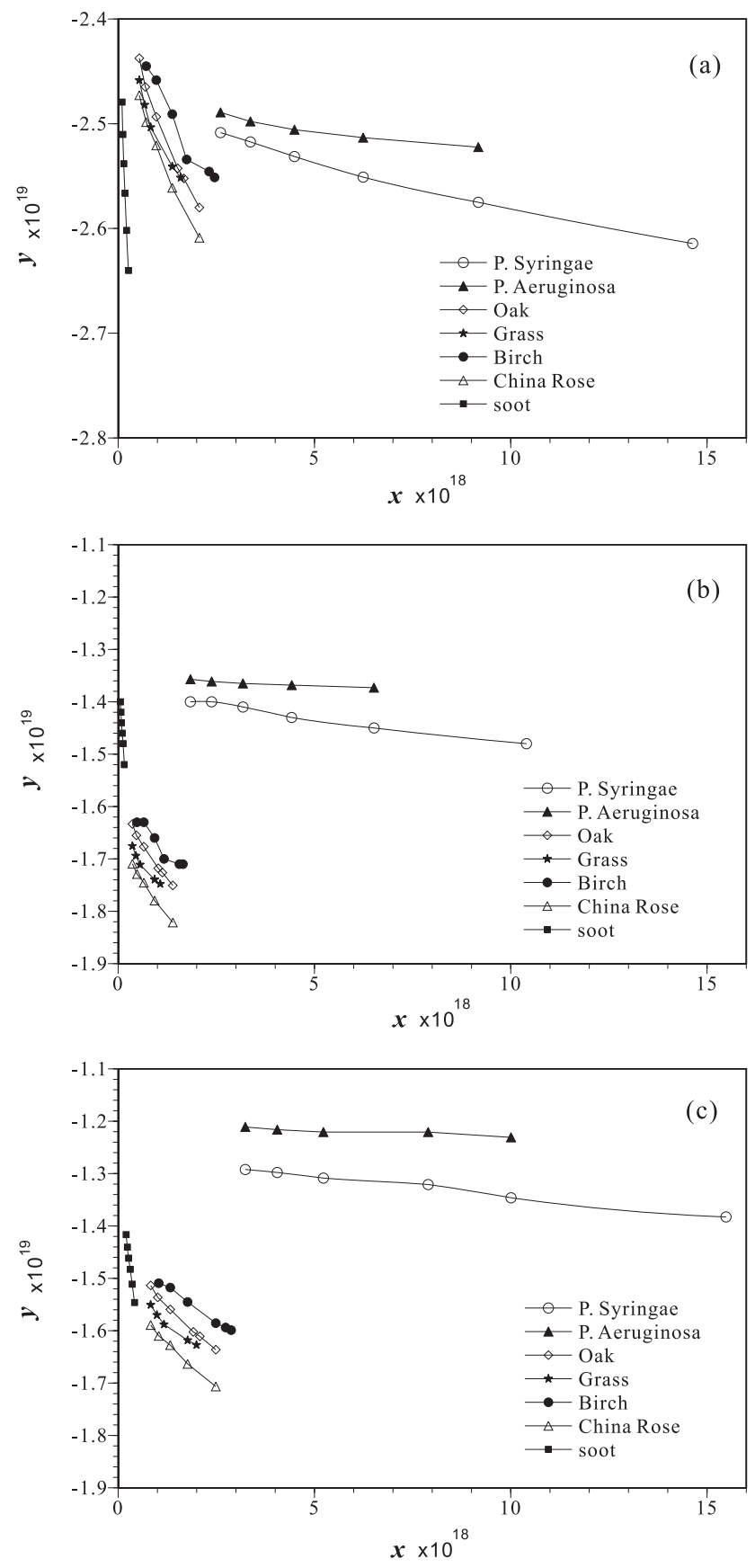

Fig. 1. Effects of various degrees of linearization. Panels (a) and (b) applies linearization from Eqs. (14a) and (16a), respectively, both without curvature adjustment; panel (c) is the same as panel (b) but with curvature adjustment. Not all species studied here are included in order to avoid cluttering of curves.

temperature range of the experimental data, it would be similar to the values calculated here, which lie between $10 \times 10^{-20}$ and $16 \times 10^{-20} \mathrm{~J}$. Pruppacher and Klett (1997, Table 7.3) also calculated $\Delta g_{a}$ but found somewhat lower values: $3 \times 10^{-20} \mathrm{~J}$ at $-36^{\circ} \mathrm{C}$ and increases to $5.4 \times 10^{-20} \mathrm{~J}$ at 

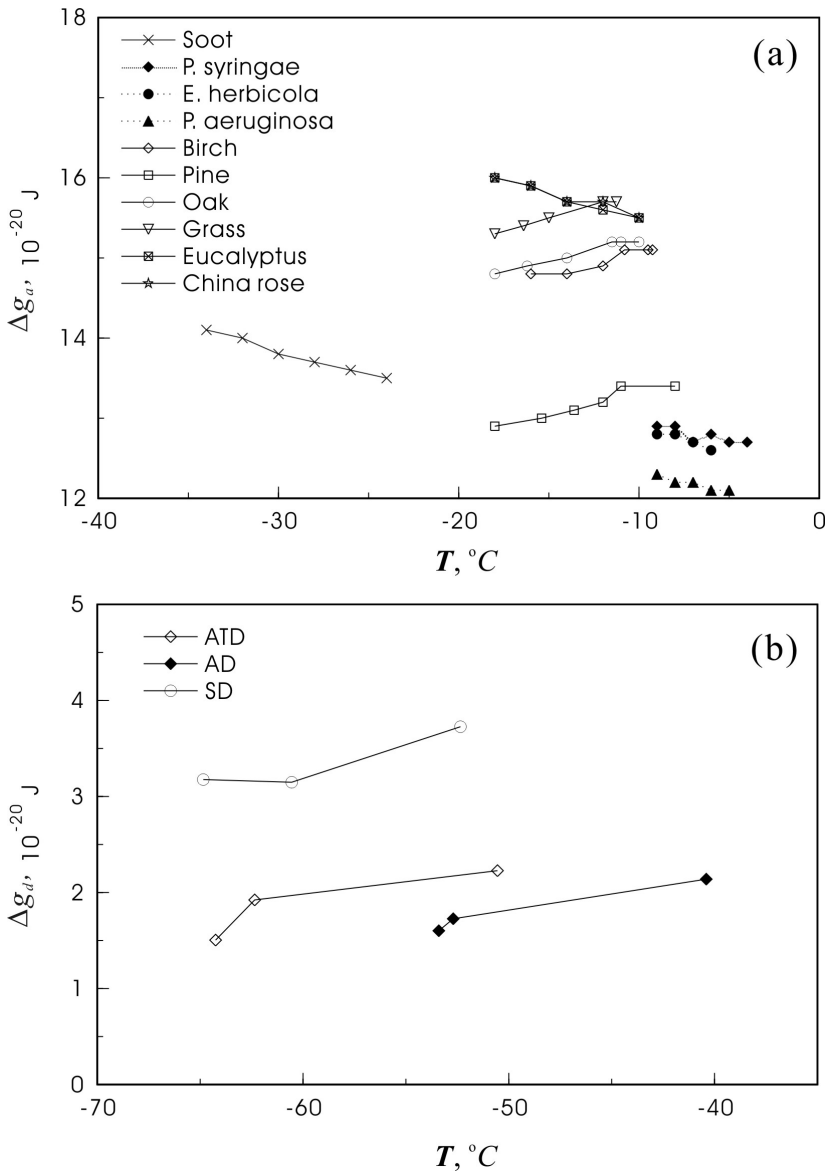

Fig. 2. Temperature dependence of the activation energy for various IN species, calculated by assuming constant $m$ according to the values given in Table 6: (a) $\Delta g_{a}$ for the freezing nucleation on other IN species; (b) $\Delta g_{d}$ for the deposition nucleation on dust. Note that the vertical scale of panel (a) does not originate from zero so the range of values is relatively small.

$-29^{\circ} \mathrm{C}$. Note that the activation energy $\Delta g_{a}$ might have different controlling mechanisms at different temperatures. Hagen et al. (1981) suggested that at temperatures warmer than $-29^{\circ} \mathrm{C}$, the transfer of water molecules across the water-ice interface is limited by the self-diffusion through the bulk water, while at temperatures lower than $-32^{\circ} \mathrm{C}$ the transfer is by large water clusters.

The values of $\Delta g^{\#}$ that we derived should be considered as averages over the temperature range of each experimental data set. In principle, one should be able to get the temperature dependence by inserting the parameters $r_{N}$ and contact angle from Table 6 along with the measured nucleation rate into Eq. (11) to get $\Delta g^{\#}$ at each measured temperature. Of course, this has to be done under the assumption that $m$ is a constant with respect to temperature. Figure 2 shows the activation energies that were calculated this way. Within each species, the variation of $\Delta g_{a}$ with temperature (Fig. 2a) is not significant compared to the theoretical estimations of Hagen et al. (1981) and Pruppacher and Klett (1997) for homogeneous nucleation. This suggests either that our method and data are not sufficient to resolve it or that there exist other factors that diminish the temperature dependence. One possible cause for the difference is that the factor $m$ also depends on temperature, and neglecting this somehow offset the temperature dependence of $\Delta g_{a}$. Thus, we tried to fix $\Delta g^{\#}$ as an alternative to calculate $m$ for each data point but found that $m$ calculated this way is nearly independent of temperature. It is also possible that the presence of IN substrate regulated the value of $\Delta g_{a}$ so its behavior deviates from that for homogeneous nucleation. As can be seen from Fig. 2a, the differences in $\Delta g_{a}$ among species are greater than for single species at different temperatures.

For the deposition nucleation mode, the activation energy is the energy of adsorption of water vapor onto the IN substrate but represented by the energy of desorption $\Delta g_{d}$. Since the adsorption process strongly depends on the properties of the substrate, one would expect the value of $\Delta g_{d}$ to change more significantly among species as compared to the changes in $\Delta g_{a}$. Indeed, our value of $\Delta g_{d}$ for SD is more than $80 \%$ greater than that for $\mathrm{AD}$, even though they are all for mineral dusts, whereas those for freezing nucleation vary within $40 \%$ among different species. Some direct measurements of $\Delta g_{d}$ can be found in the literature for comparison. Seisel et al. (2004) found the adsorption energy of water vapor on mineral dust to be $6.6 \times 10^{-20} \mathrm{~J}$; Hu and Michaelides (2007) obtained $1 \times 10^{-19} \mathrm{~J}$ for water adsorption on Kaolinite; whereas Gustafsson et al. (2005) obtained $7.6 \times 10^{-20} \mathrm{~J}$ for calcite and $8.7 \times 10^{-20} \mathrm{~J}$ in the case of Arizona Test Dust. Although our values are of the right orders of magnitude, they are somewhat lower than those found in the literature. Note that the adsorption energy is controlled by not only the chemical composition but also by the physical properties such as roughness and defects of the substrate. This implies that the way the dust samples are processed in the laboratory may influence the value of $\Delta g_{d}$. The following are a few measurement data on adsorption energy for other type of materials, which might be useful for relevant atmospheric applications: $4.9 \times 10^{-20} \mathrm{~J}$ on grey soot and $6.3 \times 10^{-20} \mathrm{~J}$ on black soot (Alcala-Jornod et al., 2002), and $1.5 \times 10^{-19} \mathrm{~J}$ for AgI (Corrin and Nelson, 1968). One can see that the difference between species is pretty much the same as that between sub-species of dusts. Also note that, as shown in Fig. 2b, $\Delta g_{d}$ of the three dust types seems to increase with rising temperature, but the magnitude is not prominent.

Contact angle is more important in determining the heterogeneous nucleation ability. Unfortunately, most of the past efforts were done for the contact angle of liquid water as enclosed by air and the substrate, which is conventionally written as $\theta_{w / a}$. Yet, the contact angles that we are considering here are for ice, as enclosed either by air and substrate $\left(\theta_{i / a}\right.$; for deposition nucleation) or by liquid water and substrate $\left(\theta_{i / w}\right.$; for freezing nucleation). One of the few attempts that we are aware of to find the contact angle of ice 
is the study of Hung et al. (2003), but those values were not measured directly but were obtained by a similar analysis as ours. Another one was reported by Marcolli et al. (2007) who suggested that the contact angle on ATD for the freezing mode is $65^{\circ}$ on average. But their analysis contains similar simplifications to the classical theory as done by Hung et al. (2003). Here we introduce an indirect way of verifying the results on contact angle.

According to the Young-Dupré relation, the contact angles can be expressed as:

$$
\begin{aligned}
& \cos \theta_{w / a}=\frac{\sigma_{s / a}-\sigma_{s / w}}{\sigma_{w / a}}, \\
& \cos \theta_{i / a}=\frac{\sigma_{s / a}-\sigma_{s / i}}{\sigma_{i / a}}, \\
& \cos \theta_{i / w}=\frac{\sigma_{s / w}-\sigma_{s / i}}{\sigma_{i / w}},
\end{aligned}
$$

where the subscripts represent the interface between any two of the following phases: liquid water $(w)$, ice $(i)$, air $(a)$ or substrate $(s)$. A closure of the equation set (22) to (24) can be obtained by using Eqs. (23) and (24) to replace $\sigma_{s / a}$ and $\sigma_{s / w}$ in Eq. (22) and obtain:

$$
\cos \theta_{w / a}=\frac{\cos \theta_{i / a} \cdot \sigma_{i / a}-\cos \theta_{i / w} \cdot \sigma_{i / w}}{\sigma_{w / a}}
$$

In this equation the values of $\sigma_{w / a}, \sigma_{i / w}$ and $\sigma_{i / a}$ (with temperature dependence) can be found in many textbooks (e.g., Pruppacher and Klett, 1997, p. 130, p. 137, p. 160). Then, using values of $\theta_{i / a}$ from the literature and values of $\theta_{i / w}$ obtained here, one may derive $\theta_{w / a}$ from Eq. (25).

If one assumes that hematite is similar to the other mineral dusts, then the freezing contact angle $\theta_{i / w}$ of hematite and the deposition contact angle $\theta_{i / a}$ of ATD, AD or SD given in Table 6 can be used to calculate $\theta_{w / a}$ according to Eq. (25). There are quite a few measurements on $\theta_{w / a}$ that can be used for comparison. For instance, Bergh (1965) observed a contact angle of less than $6^{\circ}$ on $\mathrm{SiO}_{2}$, but it increases to $40^{\circ}$ after heat treatment of the substrate; Chen et al. (1993) measured $33^{\circ}$ on $\mathrm{SiO}_{2}$ and $57^{\circ}$ on $\mathrm{Al}_{2} \mathrm{O}_{3}$; Janczuk and Zdziennicka (1994) measured $26.8^{\circ}$ on quartz; Pruppacher and Klett (1997, Table 5.2) reported $43 \sim 52^{\circ}$ on quartz (beach sand); whereas Gence (2005) reported $10.5^{\circ}$ on magnesite and $6.7^{\circ}$ on dolomite. One can see that there is a large spread in the values of water contact angle on different minerals. In any case, to derive from Eq. (25) a reasonable value of $\theta_{w / a}$ within the range reported above, $\theta_{i / w}$ must be smaller than $\theta_{i / a}$. Yet, the results for hermatite in Table 6 show just the opposite. Note that $\theta_{i / w}$ would be even larger when extrapolated to pure water situation. The above inconsistencies indicate that either we missed some aspects of the ice germ calculation or the hematite particle used by Hung et al. (2003) behave very differently from the other dust species considered here. If the latter is true, then it is still feasible to apply the above method to derive one contact angle with the knowledge of the other two. Of course, experimental data on both the deposition mode and freezing mode nucleation for the same IN species would be necessary for verification. It is also possible that the data of Hung et al. (2003) were obtained over a temperature range that is too narrow for an accurate fitting with our method, or the formula for curvature adjustment (Eq. 20) is not accurate enough.

\subsection{Application to other nucleation modes}

In Sect. 4.2 we discussed the possibility of using the contact angles in Table 6 to derive various surface tension parameters so that the results for freezing nucleation (or commonly called immersion freezing) can be applied to deposition nucleation or vice versa. It would also be interesting to know whether the results obtained here can be applied to the other two modes of heterogeneous nucleation: condensationfreezing nucleation and contact nucleation. Condensationfreezing nucleation can be treated as a two-step process: condensation nucleation followed by the immersion freezing nucleation. Without the presence of salt (solute), the occurrence of condensation nucleation requires at least some supersaturation with respect to water. Its rates can be calculated easily following formulations similar to those given in Sect. 2 and by knowing the adsorption energy and contact angle $\theta_{w / a}$, so the details will not be elaborated here. Due to the extra step of condensation nucleation, IN that have good freezing capability might not be good condensation-freezing nuclei. In this regard, pollens could be good IN for condensation-freezing nucleation because they are also efficient in condensation nucleation, partly due to their large sizes and partly because the capillary effect on pollens allows rather easy water uptake even under sub-saturated environment (Diehl et al., 2001). The presence of solute could also help the uptake of liquid water, thus enhancing the condensation nucleation but, in the mean time, depressing the probability of freezing nucleation.

The remaining heterogeneous ice nucleation is the contact nucleation, whose rate is difficult to measure in the laboratory. Cooper (1974) suggested that the contact nucleation could be calculated in a manner analogous to that for immersion freezing and deposition freezing. Of course, the probability of making contact also needs to be considered. Cooper's theoretical approach seems to be a viable way of dealing with this potentially important nucleation mechanism. Therefore, the thermodynamic parameters obtained in this study in effect can be used on all four ice nucleation modes.

Besides evaluating basic thermodynamic properties for various IN, our analysis also provide a way to broaden the application of laboratory results. For use in cloud microphysical models, laboratory results on ice nucleation are often converted into rate formulas by simple curve fitting techniques. These formulas are empirical in nature and not easy to modify to include additional factors that were not considered in 
Table 7. Examination of the effect of assigned IN size on the results of activation energy and contact angle parameters. The values shown are percentage changes for each parameter when the originally assigned $r_{N}$ is altered by one third or three times.

\begin{tabular}{lrrrr}
\hline & \multicolumn{2}{c}{ change in $\Delta g^{\#}$} & \multicolumn{2}{c}{ change in $\theta$} \\
& $1 / 3 r_{N}$ & $3 r_{N}$ & $1 / 3 r_{N}$ & $3 r_{N}$ \\
\hline Soot & $-4.8 \%$ & $5.6 \%$ & $-3.9 \%$ & $2.1 \%$ \\
E. herbicola & $-6.2 \%$ & $6.3 \%$ & $-1.9 \%$ & $0.7 \%$ \\
P. syringae & $-6.2 \%$ & $6.2 \%$ & $-2.7 \%$ & $0.0 \%$ \\
P. aeruginosa & $-5.5 \%$ & $6.3 \%$ & $0.0 \%$ & $0.0 \%$ \\
Grass & $-5.1 \%$ & $5.1 \%$ & $-0.9 \%$ & $0.8 \%$ \\
Oak & $-4.6 \%$ & $5.3 \%$ & $-0.7 \%$ & $0.2 \%$ \\
Pine & $-4.5 \%$ & $5.1 \%$ & $-0.6 \%$ & $1.2 \%$ \\
Birch & $-4.6 \%$ & $5.3 \%$ & $-0.3 \%$ & $0.7 \%$ \\
Eucalyptus & $-4.4 \%$ & $5.0 \%$ & $-0.6 \%$ & $0.6 \%$ \\
China rose & $-5.0 \%$ & $5.0 \%$ & $-0.5 \%$ & $0.5 \%$ \\
AD & $-18.13 \%$ & $19.03 \%$ & $-10.23 \%$ & $4.73 \%$ \\
SD & $-14.57 \%$ & $12.96 \%$ & $-29.22 \%$ & $11.84 \%$ \\
ATD & $-13.15 \%$ & $13.15 \%$ & $-18.81 \%$ & $8.98 \%$ \\
\hline
\end{tabular}

the experiments. By extracting the contact angle and activation energy, the empirical rate formulas can be transformed into the classical nucleation rate equation given in Eq. (1), which allows the flexibility of revising various basic parameters. For example, one can include solute effect by modifying the energy of germ formation (with water activity), so that the original experiment done for the heterogeneous freezing of pure water may be extended for application to solution freezing. A similar treatment can also be done for the curvature effect. In laboratory measurements, such as that of Möhler et al. (2006) and Field et al. (2006), the size range of IN that applied might deviate from that of naturally occurring IN. As discussed in Sect. 3.3, curvature effect may have strong influence on the nucleation rate. Therefore, rates measured for one size might not be adequately applied to other sizes. The present approach could be easily used to solve such problems.

\subsection{Uncertainties}

Even though it has been proven successful against laboratory studies, the classical theory has several apparent deficiencies. For instance, we used many bulk thermodynamic properties to describe the behavior of microscopic ice germs. Caution must be made that the contact angle is a macroscopic concept, which might not hold for the minuscule nucleation germs. Most of the contact angles mentioned in the literature were measured on a macroscopic scale. As Evans and Lane (1973) pointed out, there is a marked difference between the macroscopic contact angle and that of the ice germ due to the line tension effect. Thus, the contact angles derived here probably should be viewed as an equivalent thermodynamic quantity. Similar concerns also exist in the specific volume (density) and surface tension terms that appeared in Eqs. (5) and (7).

Inherent uncertainties also arise from some of the basic assumptions of the classical theory, such as the Boltzmann distribution and quasi-steady state assumption of germ concentration. The latter assumption can be corrected with the Zeldovich factor, but the factor itself was derived with mathematical approximations. Fortunately, the error involved is about 1\% (Pruppacher and Klett, 1997, p. 202).

Some error of estimation may also arise from the assumptions that we made. In Eq. (5) the bulk free energy of phase change $\Delta g_{b}$ may be affected by elastic strain $\varepsilon$ between the lattices across the interface (Turnbull and Vonnegut, 1952):

$\Delta g_{b}=k T \ln S_{i}-v_{w} \cdot C \cdot \varepsilon^{2}$,

where $C$ is about $1.7 \times 10^{10} \mathrm{~J} \mathrm{~m}^{-3}$. In previous discussions, we have ignored this term because very little is known about the values of $\varepsilon$. However, one may wonder how significantly the elastic strain affects our results. The misfit is typically less than a few percents between ice and most other materials. Assuming the elastic strain is on the order of $1 \%$, this would decrease the bulk free energy $\Delta g_{g}$ by less than $15 \%$ when the ice saturation ratio $S_{i}$ is above 1.1. The same estimation can be made for the freezing nucleation. The error from neglecting the strain term would cause a similar error in the factor $f$ but no obvious effect on the activation energies. However, as the contact angle and $m$ vary slowly with $f$ for the conditions considered here, we expect the error associated with the elastic strain effect to be less than $15 \%$. Other physical properties such as defects or dislocations that may enhance the nucleation capability also contribute to similar uncertainties.

A more complicated problem is the uncertainty in $r_{N}$. In the natural environment, bacteria, pollens, soot and dust particles all have large variations in $r_{N}$. The variations might be smaller for the laboratory particles mentioned in Sect. 2.1, which were pre-processed before applying them to the measurement of nucleation rates. However, the particles will never reach a mono-dispersed size distribution as we have implicitly assumed. Some of the measurements did provide particle size distribution, for which we took the modal size as the assigned $r_{N}$. But for those that did not provide size information, we have to make an educated guess according to the information provided in the published literature. Either way, the assigned $r_{N}$ must contain uncertainties. We estimated the uncertainties associated with the assumed particle size by the following analysis. For each IN species, we made two more sets of calculations, one assuming the mean particle size is one-third of the assigned $r_{N}$, and the other is three times of the assigned $r_{N}$. The results are given in Table 7 . One can see that, within this nearly one order of magnitude variation, the uncertainties in the contact angles are rather limited, except those for the mineral dusts, which may change by up to $30 \%$ for the smaller $r_{N}$. The activation energies $\Delta g^{\#}$ are more sensitive to the assigned value of $r_{N}$, particularly for 
the three dust species the values may change by up to $20 \%$. Fortunately, for the pollen species, which we are most unsure of the sizes used in the laboratory experiments, the results are quite consistent. Furthermore, the nucleation rate is not very sensitive to the variations in activation energy as discussed earlier.

Our analysis also included several idealizations that might have introduced uncertainties. For example, all IN particles were assumed spherical but in reality, few really are. In addition, particles of each IN species were assumed to have the same surface physical properties (roughness, defects, impurities, active sites, etc.), but in the real world or even in the laboratory experiments variations must exist from particle to particle. Variations in the surface chemical properties may also exist among IN of the same species. Deactivation of IN may result when they have been in contact with foreign gases or particles (Georgii and Kleinjung, 1967). Gorbunov et al. (2001) also suggested that oxidation might affect the concentration of soot's surface chemical groups thus change their ice nucleating capability, implying that not all soot should be treated the same. Unfortunately, the errors associated with these factors are difficult to evaluate.

It is important to emphasize that the contact angle and the activation energy derived in this study should not be interpreted as true physical terms when one knows so little about the mechanism of ice nucleation and acknowledges that the classical theory is tentative. The contact angle could have physical meaning under some circumstances, but one can hardly expect the surface of the nucleus to be energetically uniform. Ice most likely forms at so-called active sites, where crystalline defects or contaminants exist. If nucleation is controlled primarily by active sites on the surface of ice nuclei, and the number and strength of these sites vary significantly from particle to particle, then the singular model mentioned in the introduction would be a more appropriate concept of nucleation. Marcolli et al. (2007) also applied the classical nucleation theory to fit their measurement of heterogeneous freezing from ATD in emulsified droplets, and they found that the dependence of the heterogeneous freezing temperatures on ATD concentrations could not be described by assuming a constant contact angle for all ATD particles. They adopted the singular hypothesis and suggested that either the contact angle or the active sites vary between particles, and the former may just be a proxy of the latter. For their data to fit well with the classical nucleation theory, it requires the ice nucleation efficiency of ATD particles to be normally or log-normally distributed amongst the particles. However, their analysis did not consider the two IN-size-dependent factors - the curvature effect on surface tension and the complete form of the geometric factor given in Eq. (9). Since the size range of their ATD particles is quite large, it is possible that these size-dependent factors could cause the observed variation of "proxy nucleation ability" among particles as we have pointed out in Sect. 3.3.
Möhler et al. (2006), who performed the deposition nucleation experiment on mineral dust that is mentioned in Sect. 2.1, noted that in their experiments the formation of new ice crystals almost instantly stopped after a threshold $S_{i}$ was reached. In addition, no new ice crystals were observed when $S_{i}$ stayed almost constant at this threshold or only slightly decreased. This observation seems to indicate that time is not a primary factor and the nucleation proceeds in a singular way. However, from their experiment it is unclear whether new ice formation can occur at a fixed but lower $S_{i}$. For a pure singular nucleation, there should be no time dependence at any $S_{i}$, not just above the maximum threshold $S_{\max }$. If new ice does form in the deposition mode at a fixed $S_{i}$ that is less than $S_{\max }$, then the statistical theory should still hold (at least for the low $S_{i}$ situations). Furthermore, the singular model actually cannot explain why there should exist a threshold $S_{\max }$, and why this threshold value should depend on the cooling rate as observed by Möhler et al. (2006). Note that the classical theory also predicts a reversal (or threshold) point below which the freezing nucleation rate actually decreases with decreasing temperature, because the activation energy in Eq. (10) becomes very high as the parent phase (water) becomes more viscous. But the temperature for this to occur is usually too low for atmospheric relevance, and certainly does not apply to the deposition nucleation.

Vali and Stansbury (1966) suggested a "modified singular model" for which the stochastic effects may co-exist with the singular temperature effect. They found that the heterogeneous freezing of droplets at constant temperature does not stop but with a rate decreasing exponentially with time. In their experiments on immersion freezing by bacteria, Yankofsky et al. (1981) found that under a constant temperature there was first a period of fast nucleation followed by a slow nucleation phase, suggesting that the freezing is probably a combination of stochastic and singular nucleation. A recently study by Vali (2008) assessed the relative roles of temperature and time-dependence of immersion freezing and reasoned that the former has primary importance while the latter could also contribute, thus advocating for the modified singular model. It is possible that, in situations when the nucleation is determined by the favored sites, the nucleation rate varies sharply from negligible to significant over a very narrow range of nucleation conditions (i.e., temperature or supersaturation), so the stochastic nature becomes unobservable and nucleation appear to be dominated by the singular mechanism. However, evidences supporting the classical statistical theory are also abundant (see discussions given in Pruppacher and Klett (1997, 351-353 pp.) and in Vali (2008)). Very likely that both the statistical and singular mechanisms are functioning, but which one is dominating depends on the types of IN and diversity of surface properties within the particular IN population, as well as the ambient conditions. The fact that our analysis with the classical theory seems to work well may indicate that the nucleation 
data we analyzed were taken at the regime of statistical nucleation, such as during the fast nucleation stage of Yankofsky et al. (1981) or the low saturation period of Möhler et al. (2006).

With many of the above assumptions or uncertainties, it might be more appropriate to call the results derived from the classical theory the "apparent" parameters, such as the "apparent activation energy" and "apparent contact angle." Thus, one may regard the neglected factors, such as the elastic strain effect, to have been embedded into the contact angle in our analysis. But it is doubtful that the singular concept can also be bundled together.

\section{Summary and Conclusion}

Comprehensive representations of heterogeneous ice nucleation rate were achieved by a combination of classical theory and experimental data, from which we derived the activation energy and contact angle for various ice nuclei (including soot, bacteria, pollen, and mineral dust) that are important to the formation of ice in clouds. When these thermodynamic parameters are established, one will be able to describe ice nucleating behavior in clouds pertaining to a particular species of ice nuclei with the knowledge of their size distributions.

The activation energy for freezing nucleation does not vary much among different IN species, whereas larger variability exits in the activation energy for deposition nucleation even among similar types of IN (e.g. three types of mineral dusts). Furthermore, the latter are about an order of magnitude lower than the former. It is important to note that under most circumstances, the activation energy is not critical to the calculation of nucleation rate.

Contact angle is a key parameter in determining the nucleation capability of IN. Among the IN species that are analyzed here, bacteria have the smallest contact angle of ice germ and are thus the most effective in initiating freezing nucleation. Pollens also have relatively small contact angle of ice-germ formation. In addition, they also have the advantage of large sizes and water absorbing surface for acquiring liquid water, thus are efficient in ice nucleation via both freezing and condensation-freezing. Soot has relatively large contact angle thus is less efficient in freezing nucleation. One type of mineral dust (hematite) analyzed here shows even larger contact angles for freezing nucleation. However, for deposition nucleation, three other types of mineral dusts show rather small contact angle thus are effective IN.

Our detailed analyses considered the Zeldovich factor for modification of ice germ formation, the particle-size dependent geometric factor for the calculation of wetting coefficient, as well as the solute and curvature effects on surface tension, thus the value of contact angle and energy of ice germ formation. All these factors to various degrees influence contact angle, and should be taken into consideration in the theoretical calculation of nucleation rates. We also discussed a possible closure calculation connecting the three surface tensions in the ice-substratemedium system. With these calculations, the contact angle for deposition nucleation can be used to obtain the contact angle for freezing nucleation or vice versa. Unfortunately, current data are not sufficient for verification of these calculations. We suggest future measurements to be conducted for both the immersion freezing and deposition nucleation on the same type of IN.

Considering the microscopic nature of the ice germ that may deviate from that measured in the bulk, as well as various uncertainties involved in our analysis, it might be more appropriate to view the contact angle and the activation energy derived here as the "apparent" parameters. When applied to theoretical formulations, these apparent parameters should nevertheless give nucleation rates close to those from laboratory measurements.

Our approach makes laboratory data more useful because factors (e.g. solute effect or curvature effect) that were not considered in the experiment can still be incorporated into the rate equations. Furthermore, the same equation can be easily applied to different IN and different nucleation modes by simply changing the relevant thermodynamic parameters (e.g. contact angle and activation energy). It is also desirable to apply our method in future laboratory work to analyze the measurement data so as to gain more thorough understanding of the physical mechanisms of ice nucleation process. Additional asset may be gained if the laboratory measurements could be performed on both the deposition and freezing modes of the same IN species so that a closure analysis of the contact angles and surface tensions between different phases may be obtained. This approach can not only provide more physical insight but also serve for result verification.

Acknowledgements. This research was supported under Grants NSC 96-2475-M-002-009 and 97-2111-M-002, as well as Grant NSC 96-2752-M-002-013-PAE and NSC 97-2725-M-002-012PAE.

Edited by: T. Koop

\section{References}

Archuleta, C. M., DeMott, P. J., and Kreidenweis, S. M.: Ice nucleation by surrogates for atmospheric mineral dust and mineral dust/sulfate particles at cirrus temperatures, Atmos. Chem. Phys., 5, 2617-2634, 2005,

http://www.atmos-chem-phys.net/5/2617/2005/.

Alcala-Jornod, C., van den Bergh, H., and Rossi, M. J.: Can soot particles emitted by airplane exhaust contribute to the formation of aviation contrails and cirrus clouds?, Geophys. Res. Lett., 29, 1820, doi:10.1029/2001GL014115, 2002.

Barth, M., McFadden, J. P., Sun, J., et al.: Coupling between Land Ecosystems and the Atmospheric Hydrologic Cycle through 
Biogenic Aerosol Pathways, B. Am. Meteorol. Soc., 86, 17381742, 2005.

Bergh, A. A.: The correlation between water contact angle and KPR adherence on $\mathrm{SiO}_{2}$ surfaces, J. Electrochem. Soc., 112, 457-458, 1965.

Bowdle, D.A., Hobbs, P. V. and Radke, L.F.: Particles in the lower troposphere over the High Plains of the United States. Part III: Ice nuclei, J. Appl. Meteorol., 24, 1370-1376, 1985.

Bragg, L. H.: Pollen size variation in selected grass taxa, Ecology, 50, 124-127, 1969.

Brandl, M. T., Quiñones, B., and Lindow, S. E.: Heterogeneous transcription of an indoleacetic acid biosynthetic gene in Erwinia herbicola on plant surfaces, P. Natl. Acad. Sci. USA, 98, 34543459, doi:10.1073/pnas.061014498, 2001.

Bryant, G. W., Hallett, J., and Mason, B. J.: The epitaxial growth of ice on single-crystalline substrates, J. Phys. Chem. Solids, 12, 189-195, 1959.

Carte, A. E. and Mossop, S. C.: Measurements of the concentration of atmospheric ice nuclei in Southern Africa, Bull. Obs. Puy de Dome, 4, 137-149, 1960.

Chen, C.-C., Hung, L.-C., and Hsu, H.-K.: Heterogeneous nucleation of water vapor on particles of $\mathrm{SiO} 2, \mathrm{Al} 2 \mathrm{O} 3$, $\mathrm{TiO} 2$, and carbon black, J. Colloid Interf. Sci., 157, 465-477, 1993.

Chen, J.-P.: Theory of deliquescence and modified Köhler curves, J. Atmos. Sci., 51, 3505-3516, 1994.

Chen, J.-P., Wang, Z., Young, C.-Y., Tsai, F., Tsai, I.-C., Wang, G.-J., Shieh, W.-C., Lin, H. W., Huang, J.-Y., and Lu, M.-J.: Simulations of Asian yellow dust incursion over Taiwan for the spring of 2002 and 2003, Terr. Atmos. Ocean. Sci., 15, 949-981, 2004.

Cooper, W.: A possible mechanism for contact nucleation. J. Atmos. Sci., 31, 1832-1837, 1974.

Cooper, W. A. and Saunders, C. P. R.: Winter storms over the San Juan Mountains. Part II: Microphysical processes, J. Appl. Meteorol., 19, 927-941, 1980.

Corrin, M. L. and Nelson, J. A.: Energetics of the Adsorption of Water Vapor on "Pure" Silver Iodide. J. Phys. Chem., 72, 643645, 1968.

Cotton, W. R., Stephens, M. A., Nehrkorn, T., and Tripoli, G. J.: The Colorado State University three-dimensional cloud/mesoscale model - 1982. Part II: An ice phase parameterization, J. Rech. Atmos., 16, 295-320, 1982.

DeMott, P. J.: An Exploratory Study of Ice Nucleation by Soot Aerosols, J. Appl. Meteorol., 29, 1072-1079, 1990.

DeMott, P. J. and Rogers, D. C.: Freezing nucleation rates of dilute solution droplets measured between -30 and $-40^{\circ} \mathrm{C}$ in laboratory simulations of natural clouds, J. Atmos. Sci., 47, 10561064, 1990.

DeMott, P. J., Rogers, D. C., Kreidenweis, S. M., Chen, Y. L., Twohy, C. H., Baumgardner, D., Heymsfield, A. J., and Chan, K. R.: The role of heterogeneous freezing nucleation in upper tropospheric clouds: Inferences from SUCCESS, Geophys. Res. Lett., 25, 1387-1390, 1998.

Diehl, K., Quick, C., Matthias-Maser, S., Mitra, S. K. and Jaenicke, R.: The ice nucleating ability of pollen, Part I: Laboratory studies in deposition and condensation freezing modes, Atmos. Res., 58, 75-87, 2001.

Diehl, K., Matthias-Maser, S., Jaenicke, R., and Mitra, S. K.: The ice nucleating ability of pollen: Part II. Laboratory studies in immersion and contact freezing modes, Atmos. Res., 61, 125133, 2002.

Dingle, A. N.: Pollen as condensation nuclei, J. Rech. Atmos., 2, 232-237, 1966.

Dorsey, N. E.: The freezing of supercooled water, T. Am. Philos. Soc., 38, 248-328, 1948.

Dufour, L. and Defay, R.: Thermodynamics of Clouds, International Geophysics Series Volume 6, Academic Press, New York and London, 1963.

Durham, O. C.: Methods in aerobiology, J. Aviation Med., 12, 153 $162,1941$.

Dymarska, M., Murray, B. J., Sun, L., Eastwood, M. L., Knopf, D. A. and Bertram, A. K.: Deposition ice nucleation on soot at temperatures relevant for the lower troposphere. J. Geophys. Res., 111, D04204, doi:10.1029/2005JD006627, 2006.

Eadie, W. J.: A molecular Theory of the Homogeneous Nucleation of Ice from Supercooled Water. Ph.D. thesis, Department of Geophysical Sciences, University of Chicago, 1971.

Evans, L. F. and Lane, J. E.: Line tension and ice nucleation theory, J. Atmos. Sci., 30, 326-331, 1973.

Field, P. R., Möhler, O., Connolly, P., Krämer, M., Cotton, R., Heymsfield, A. J., Saathoff, H., and Schnaiter, M.: Some ice nucleation characteristics of Asian and Saharan desert dust, Atmos. Chem. Phys., 6, 2991-3006, 2006, http://www.atmos-chem-phys.net/6/2991/2006/.

Fletcher, N. H.: Size Effect in Heterogeneous Nucleation, J. Chem. Phys., 29, 572-576, 1958.

Fletcher, N. H.: The Physics of Rainclouds, Cambridge University Press, 1962.

Gence, N.: Wetting behavior of magnesite and dolomite surfaces, Appl. Surf. Sci., 252, 3744-3750, 2006.

Georgii, H. W. and Kleinjung, E.: Relations between the chemical composition of atmospheric aerosol particles and the concentration of natural ice nuclei, J. Rech. Atmos., 3, 145-156, 1967.

Gorbunov, B., Baklanov, A., Kakutkina, N., Windsor, H., and Toumi, R.: Ice nucleation on soot particles, J. Aerosol Sci., 32, 199-215, 2001.

Gultepe, I., Isaac, G. A., and Cober, S. G.: Ice crystal concentration versus temperature, Int. J. Climatol., 21, 1281-1302, 2001.

Gustafsson, R. J., Orlov, A., Badger, C. L., Griffiths, P. T., Cox, R. A., and Lambert, R. M.: A comprehensive evaluation of water uptake on atmospherically relevant mineral surfaces: DRIFT spectroscopy, thermogravimetric analysis and aerosol growth measurements, Atmos. Chem. Phys., 5, 3415-3421, 2005, http://www.atmos-chem-phys.net/5/3415/2005/.

Hagen, D. E., Anderson, R. J., and Kassner Jr., J. L.: Homogeneous condensation-freezing nucleation rate measurements for small water droplets in an expansion cloud chamber, J. Atmos. Sci., 38, 1236-1243, 1981.

Hallett, J. B., Gardiner, B., Hudson, J. and Rogers, F.: Cloud condensation and ice nucleation of a range of carbonaceous aerosols. Preprints, Amer. Meteor. Soc. Conf. on Cloud Physics, Vol. 2, Snowmass, Amer. Meteor. Soc., 9-12, 1986.

Harrington, J. B. and Metzger, K.: Ragweed pollen density, Am. J. Bot., 50, 532-539, 1963.

Hazra, A., Saha, M., De, U. K., Mukherjee, J., and Goswami, K.: Study of ice nucleating characteristics of Pseudomonas aeruginosa, J. Aerosol Sci., 35, 1405-1414, 2004. 
Heffernan, K. J. and Bracewell, R. N.: Comparison of Florida and California freezing-nucleus measurements, January 1957, J. Meteorol., 16, 337-339, 1959.

Heymsfield, A. J. and Sabin, R. M.: Cirrus crystal nucleation by homogeneous freezing of solution droplets, J. Atmos. Sci., 46, 2252-2264, 1989.

Hobbs, P. V. and Locatelli, J. D.: Ice Nucleation from a natural forest fire, J. Appl. Meteorol., 8, 833-834, 1969.

Hobbs, P. V.: Ice Physics, Oxford, Clarendon, 837 pp., 1974.

$\mathrm{Hu}, \mathrm{X}$. L. and Michaelides, A.: Ice formation on kaolinite: Lattice match or amphoterism?, Surf. Sci., 601, 5378-5381, 2007.

Huffman, P. J.: Supersaturation spectra of AgI and natural ice nuclei, J. Appl. Meteorol., 12, 1080-1082, 1973.

Hung, H. M., Malinowski, A., and Martin, S. T.: Kinetics of heterogeneous ice nucleation on the surfaces of mineral dust cores inserted into aqueous ammonium sulfate particles, J. Phys. Chem. A, 107, 1296-1306, 2003.

Hussain, K. and Saunders, C. P. R.: Ice nucleus measurement with a continuous flow chamber, Q. J. Roy. Meteor. Soc., 110, 75-84, 1984.

Isono, K. and Komabayasi, M.: Volcanoes as a source of atmospheric ice nuclei, J. Meteorol. Soc. Jpn., 32, 345-353, 1954.

Isono, K., Komabayasi, M., and Ono, A.: The nature and origin of ice nuclei in the atmosphere, J. Meteorol. Soc. Jpn., 37, 211-233, 1959.

Janczuk, B. and Zdziennicka, A.: A study on the components of surface free energy of quartz from contact angle measurements, J. Mater. Sci., 29, 3559-3564, 1994.

Kishcha, P., Barnaba, F., Gobbi, G. P., Alpert, P., Shtivelman, A., Krichak, S. O., and Joseph, J. H.: Vertical distribution of Saharan dust over Rome (Italy): Comparison between 3-year model predictions and lidar soundings, J. Geophys. Res., 110, D06208, doi:10.1029/2004JD005480, 2005.

Khvorostyanov, V. I. and Curry, J. A.: The theory of ice nucleation by heterogeneous freezing of deliquescent mixed CCN. Part I: Critical radius, energy, and nucleation rate, J. Atmos. Sci., 61, 2676-2691, 2004.

Korolev, A. V., Isaac, G. A., Cober, S. G., Strapp, J. W., and Hallett, J.: Microphysical characterization of mixed-phase clouds, Q. J. Roy. Meteor. Soc., 129, 39-65, 2003.

Kumai, M.: Electron microscope study of snow crystal nuclei, J. Meteorol., 18, 151-156, 1951.

Langer, G.: Evaluation of NCAR ice nucleus counter. Part I: Basic operation, J. Appl. Meteorol., 12, 1000-1011, 1973.

Lau, K.-M. and Wu, H.-T.: Warm rain processes over tropical oceans and climate implications, Geophys. Res. Lett., 30, 22902294, 2003.

Levin, Z., Yankofsky, S. A., Pardes, D., and Magal, N.: Possible application of bacterial condensation freezing to artificial rainfall enhancement, J. Clim. Appl. Meteorol., 26, 1188-1197, 1987.

Lighthart, B.: The ecology of bacteria in the alfresco atmosphere, FEMS Microbiol. Ecol., 23, 263-274, 1997.

Lindow, S. E.: The importance of bacterial ice nuclei in plant frost injury, Curr. Top. Plant Biochem. Physiol., 2, 119-128, 1983.

Lin, Y.-L., Farley, R. D., and Orville, H. D.: Bulk parameterization of the snow field in a cloud model, J. Clim. Appl. Meteorol., 22, 1065-1089, 1983.

Liu, X. Y.: A new kinetic model for three-dimensional heterogeneous nucleation, J. Chem. Phys., 111, 1628-1635, 1999.
Lu, H. M. and Jiang, Q.: Size-dependent surface energies of nanocrystals, J. Phys. Chem., 108, 5617-5619, 2004.

Maki, L. R., Galyan, E. L., Chang-Chien, M. M., and Caldwell, D. R.: Ice Nucleation induced by Pseudomonas syringae, Appl. Environ. Microb., 28, 456-459, 1974.

Mansvelt, E. L. and Hattingh, M. J.: Scanning electron microscopy of invasion of apple leaves and blossoms by Pseudomonas syringea pv. Syringae, Appl. Environ. Microb., 55, 533-538, 1989.

Marcolli, C., Gedamke, S., Peter, T. and Zobrist, B.: Efficiency of immersion mode ice nucleation on surrogates of mineral dust, Atmos. Chem. Phys., 7, 5081-5091, 2007, http://www.atmos-chem-phys.net/7/5081/2007/.

Mason, B. J.: The Physics of Clouds, Oxford, Clarendon Press, 1971.

Meyers, M. P., DeMott, P. J., and Cotton, W. R.: New primary icenucleation parameterizations in an explicit cloud model, J. Appl. Meteorol., 31, 708-721, 1992.

Miller, H. J., Quinn, C. E., and Graham, D. C.: A strain of Erwinia herbicola pathogenic on Gypsophila paniculata, Neth. J. Pl. Pathol., 87, 167-172, 1981.

Möhler, O., Field, P. R., Connolly, P., Benz, S., Saathoff, H., Schnaiter, M., Wagner, R., Cotton, R., Krämer, M., Mangold, A., and Heymsfield, A. J.: Efficiency of the deposition mode ice nucleation on mineral dust particles, Atmos. Chem. Phys., 6, 3007-3021, 2006, http://www.atmos-chem-phys.net/6/3007/2006/.

Pasken, R. and Pietrowicz, J. A.: Using dispersion and mesoscale meteorological models to forecast pollen concentrations, Atmos. Environ., 39, 7689-7701, 2005.

Reisner, J., Rasmussen, R. M., and Bruintjes, R. T.: Explicit forecasting of supercooled liquid water in winter storms using the MM5 mesoscale model, Q. J. Roy. Meteor. Soc., 124, 10711107, 1998.

Plotkowski, M. C., Chevillard, M., Pierrot, D., Altenmayer, D. Zahm, J. M., Colliot, G., and Puchelle, E.: Differential adhesion of Pseudomonas aeruginosa to human respiratory epithelial cells in primary culture, J. Clin. Invest., 87, 2018-2028, 1991.

Pruppacher, H. R. and Klett, J. D.: Microphysics of clouds and precipitation, Kluwer, Netherlands, 954 pp., 1997.

Ruggles, J. A., Nemecek-Marshall, M., and Fall, R.: Kinetics of appearance and disappearance of classes of bacterial ice nuclei support an aggregation model for ice nucleus assembly, J. Bacteriol., 175, 7216-7221, 1993.

Schnell, R. C.: Biogenic sources of atmospheric ice nuclei, Univ. of Wyoming. Report No. AR111, 45 pp., 1974.

Schnell, R. C. and Vali, G.: World wide source of leaf derived freezing nuclei, Nature, 246, 212-213, 1973.

Seisel, S., Pashkova, A. Lian, Y., and Zellner, R.: Water uptake on mineral dust and soot: A fundamental view of the hydrophilicity of atmospheric particles?, Faraday Discuss., 130, 437-451, doi:10.1039/b417449f, 2005.

Stein, D. and Georgii, H. W.: Investigation on the saturation spectra of ice nuclei. Idojaras, J. Hungarian Meteorological Service, 86, p. 124, 1982.

Ström, J. and Ohlsson, S.: In situ measurements of enhanced crystal number densities in cirrus clouds caused by aircraft exhaust, J. Geophys. Res., 103, 11355-11 361, 1998.

Tolman, R. C.: The effect of droplet size on surface tension, J. Chem. Phys., 17, 333-337, 1949. 
Turnbull, D. and Fisher, J. C.: Rate of nucleation in condensed systems, J. Chem. Phys., 17, 71-73, 1949.

Turnbull, D. and Vonnegut, B.: Nucleation catalysis, Ind. Eng. Chem., 44, 1292-1298, 1952.

Uno, I., Carmichael, G. R., Streets, D., Satake, S., Takemura, T., Woo, J.-H., Uematsu, M., and Ohta, S.: Analysis of surface black carbon distributions during ACE-Asia using a regional-scale aerosol model, J. Geophys. Res., 108(D23), 8636, doi:10.1029/2002JD003252, 2003.

Vali, G.: Repeatability and randomness in heterogeneous freezing nucleation, Atmos. Chem. Phys., 8, 5017-5031, 2008, http://www.atmos-chem-phys.net/8/5017/2008/.

Vali, G., Cristensen, M., Fresh, R. W., Galyan, E. L., Maki, L. R., and Schnell, R. C.: Biogenic ice nuclei. II. Bacterial sources, J. Atmos. Sci., 33, 1565-1570, 1976.
Vali, G. and Stansbury, E. J.: Time dependent characteristics of the heterogeneous nucleation of ice, Can. J. Phys., 44, 477-502, 1966.

Vehkamäki, H., Määttänen, A., Lauri, A., Napari, I., and Kulmala, M.: Technical Note: The heterogeneous Zeldovich factor, Atmos. Chem. Phys., 7, 309-313, 2007, http://www.atmos-chem-phys.net/7/309/2007/.

von Blohn, N., Mitra, S. K., Diehl, K., and Borrmann, S.: The ice nucleating ability of pollen, Part III: New laboratory studies in immersion and contact freezing modes including more pollen types, Atmos. Res., 78, 182-189, 2005.

Wisner, C., Orville, H. D., and Meyers, C.: A numerical model of a hail-bearing cloud, J. Atmos. Sci., 29, 1160-1181, 1972.

Yankofsky, S. A., Levin, Z., Bertold, T., and Sandlerman, N.: Some basic characteristics of bacterial freezing nuclei, J. Appl. Meteorol., 20, 1013-1019, 1981. 